\title{
Brittle rupture of an aged HPDE geomembrane at local gravel indentations under simulated field conditions
}

\author{
F. B. Abdelaal ${ }^{1}$, R. K. Rowe ${ }^{2}$ and R. W. I. Brachman ${ }^{3}$ \\ ${ }^{1}$ Graduate Student, GeoEngineering Centre at Queen's-RMC, Queen's University, Kingston, ON, \\ Canada, K7L 3N6, Telephone: +1 613533 3096; Telefax: +16135332128; \\ E-mail:fady.badran@ce.queensu.ca \\ ${ }^{2}$ Professor and Canada Research Chair in Geotechnical and Geoenvironmental Engineering, \\ GeoEngineering Centre at Queen's-RMC, Queen's University, Ellis Hall, Kingston, ON, Canada K7L \\ 3N6, Telephone: +1613533 3113; Telefax: +16135332128; E-mail: kerry@civil.queensu.ca \\ ${ }^{3}$ Professor, GeoEngineering Centre at Queen's-RMC, Queen's University, Kingston, ON, Canada, K7L \\ 3N6, Telephone: +1613533 3096; Telefax:+16135332128; E-mail: brachman@civil.queensu.ca
}

Received 8 February 2013, revised 24 October 2013, accepted 8 November 2013

\begin{abstract}
The susceptibility of a $1.5 \mathrm{~mm}$ thick high-density polyethylene geomembrane to brittle rupture from long-term stress cracking in a simulated municipal solid waste landfill liner is examined. The geomembrane was pre-aged in a leachate at $85^{\circ} \mathrm{C}$ to lower the notched constant tensile load stress crack resistance of the geomembrane to about $75 \mathrm{~h}$. The aged geomembrane was then used as part of a composite liner system in geosynthetic liner longevity simulators (GLLSs) with a geosynthetic clay liner and sand foundation layer below the geomembrane and a $560 \mathrm{~g} / \mathrm{m}^{2}$ geotextile protection layer and $50 \mathrm{~mm}$ drainage gravel above the geomembrane. The GLLSs allow the simulation of field conditions including elevated temperatures, overburden pressure, leachate circulation, and composite liner exposure conditions. The geomembrane experienced brittle rupture on the side slopes of the local gravel indentations for temperatures between 55 and $85^{\circ} \mathrm{C}$. The higher the liner temperature, the shorter the time to rupture and the higher the tensile strain at rupture. Arrhenius modelling of the test data gave an activation energy of $E_{\mathrm{a}}=112 \mathrm{~kJ} / \mathrm{mol}$.
\end{abstract}

KEYWORDS: Geosynthetics, Geomembranes, High density polyethylene, Service life, Landfills, Stress cracking, Durability, Rupture, Crack initiation.

REFERENCE: Abdelaal, F. B., Rowe, R. K. and Brachman, R. W. I. (2014). Brittle rupture of an aged HPDE geomembrane at local gravel indentations under simulated field conditions. Geosynthetics

International, 21, No. 1, 1-23. [http://dx.doi.org/10.1680/gein.13.00031]

\section{INTRODUCTION}

A recent survey of landfill liner requirements in 52 countries (Koerner et al. 2010), indicated that $65 \%$ required a geomembrane (GMB) liner as a part of the liner system for hazardous waste, $62 \%$ for municipal waste and $40 \%$ for inert waste landfills. GMB liners are usually used in combination with a low hydraulic conductivity layer that can be either a compacted clay (CCL) or geosynthetic clay liner (GCL) to form a composite liner system. Above the composite liner and just below the waste, a primary leachate collection layer having coarse drainage soil (typically gravel) is used to collect the fluids at the bottom of the landfill. A protection layer (typically a needle-punched nonwoven geotextile) is usually used between the drainage layer and the GMB liner to protect the GMB from the gravel particles.

The role of the GMB liner is to minimise the leakage (advection) of fluids (leachate and gas) and the diffusion of most contaminants in those fluids to the underlying soil and/or ground water (Rowe 2012). The GMB can effectively maintain this role as long as it remains essentially intact.

Assuming good CQA/CQC and a leak detection survey (e.g., Darilek et al. 1989; ASTM D 6747) one might expect minimal holes (typically $\leqslant 5$ holes/ha) when the waste is placed in the landfill. Upon placement of the waste, the increase in the overburden pressure will cause the gravel particles in the drainage layer to locally deform the liner inducing tensile strains in the GMB. These tensile strains may cause short-term gravel punctures in 
GMB liners (e.g., Gudina 2007). Research has shown that these short-term (ductile) punctures can be minimised by the selection of a suitable protection layer (Narejo et al. 1996; Koerner et al. 1996; Tognon et al. 2000; Gudina and Brachman 2006; Dickinson and Brachman 2008; Koerner et al. 2010; Brachman et al. 2011). Assuming sufficient protection to avoid short-term puncture, the second possible mechanism for hole formation after waste placement is 'long-term' rupture of the GMB liner due to stress cracking that is most likely related to the magnitude of the sustained tensile strains in the GMB following installation at local gravel indentations, the stress crack resistance of the GMB, and temperature. Seeger and Müller (2003) indicated that $3 \%$ is a conservative estimate for the long-term allowable tensile strain that should not be exceeded to safeguard the GMB liner against stress cracking for at least 100 years of service life. This can be achieved by selecting a proper protection layer aiming to limit the tensile strains in the GMB liner to prevent stress cracking rather than only preventing short-term puncturing (Seeger and Müller 1996, 2003). Numerous short-term physical experiments have examined the magnitude of the strains induced by drainage gravel for GMBs with different protection layers and clay liners (Tognon et al. 2000; Gudina and Brachman 2006;Dickinson and Brachman 2008; Brachman and Gudina 2008a, 2008b; Gudina and Brachman 2011; Hornsey and Wishaw 2012). However, since these experiments were intended to quantify the demand (i.e., the local tensile strains that may develop in the GMB) they were not run sufficiently long enough to assess the potential long-term GMB resistance - specifically, whether or not the geomembrane can rupture under sustained tensile strains.

The short-term studies of the strains in GMBs typically show strains in excess of the 3\% suggested by Seeger and Müller (2003) as a maximum allowable strain. This prompts the question as to what happens to a GMB if these tensile strains are sustained as the geomembrane experiences degradation of its properties. One hypothesis is that relaxation will sufficiently reduce the tensile stress such that cracking does not occur. The alternative hypothesis is that sustained tensile strains and a decrease in the GMBs stress crack resistance with time can result in rupturing (i.e., fully penetrating stress cracks) of the GMB at location of sufficiently high tensile strain. Narejo et al. (1996) proposed empirical tables for creep and degradation reduction factors trying to project their short-term results into long-term behaviour for their design equation. Koerner et al. (2010) presented long-term results for four pressure vessels with truncated cones using $1.5 \mathrm{~mm}$ highdensity polyethylene (HDPE) GMB and a $600 \mathrm{~g} / \mathrm{m}^{2}$ nonwoven needle-punched geotextile protection layer. After 10 years of testing, they found 'subtle yield' with $12 \mathrm{~mm}$ cone tips under 430 and $580 \mathrm{kPa}$ applied pressure. With $38 \mathrm{~mm}$ cone tips, they found 'pronounced yield' under $34 \mathrm{kPa}$, and 'pronounced yield' with one 'break' under $52 \mathrm{kPa}$. They updated the creep reduction factors proposed by Narejo et al. (1996) with more restrictive values. Despite the fact that one of the tested GMB samples failed in these long-term tests, it was not clear if the GMB failed due to brittle stress cracking or ductile puncture, although the repeated use of the word 'yield' suggests ductile failure at the location below the truncated cone. To date no study has examined the potential for stress cracking under simulated landfill liner conditions.

The objective of this paper is to examine the performance of a GMB in a composite liner under simulated landfill conditions in a relatively large test apparatus that allows construction of a full liner system and the use of the same materials used in the field. The specific questions to be examined are: (a) will the GMB experience stress cracking under simulated field conditions and, if so, (b) what affects the location of any cracks, (c) what is the effect of liner temperature on the time-to-failure and the tensile strains at failure at any cracks, and (d) what is the nature of the rupture surfaces in the GMB.

\section{BACKGROUND}

Long-term stress cracking discussed herein is defined as 'an external or internal crack in a plastic caused by tensile stresses less than its short-term mechanical strength' (ASTM D 5397). Because HDPE GMBs are partially crystalline thermoplastics ( $40 \sim 50 \%$ crystallinity) they can fail due to stress cracking which involves slow, brittle crack growth (Hsuan 2000) with propagation velocities less than $0.1 \mathrm{~m} / \mathrm{s}$ (Kinloch and Young 1983) under the long-term effect of a low-level stress (Müller 2007). According to Lu and Brown (1990), for loaded notched specimens in uniaxial tension, slow crack growth involves: (a) the formation of the craze (small, highly strained, micro-voided fibrillar region (Kay et al. 2004)) at the tip of the notch; (b) growth of the craze zone; (c) rupture of the fibrils at the base of the craze where each fibril undergoes necking and fails by shear thinning; (d) crack growth at an accelerated rate; and (e) ultimate rupture of the specimen by yielding of the remaining ligament. Studies (e.g., Lu and Brown 1990; Hsuan 2000) have shown that polyethylene undergoes three distinct modes of failure: (a) ductile failure at high stress levels which occurs in a relatively short time after loading and is associated with macroscopic yielding and is dominated by the creep rate; (b) brittle failure at low stress levels at relatively long time after loading that is associated with slow crack growth initiated from defects in the sample; and (c) transition zone at stress levels between the ductile and brittle regions.

In addition to the applied stresses, stress cracking of polymers is accelerated by chemical exposure (Kay et al. 2004; Müller 2007; Scheirs 2009). Sensitising agents with lubricating effects such as polar liquids, detergent solution, oils, halogenated hydrocarbons, etc., can increase the rate of slow crack growth by causing disentanglements of tie molecules in the amorphous region adjoining crystal lamellae (Kay et al. 2004). Ward et al. (1990) showed that failure of a notched specimen in solution with a surfactant (10\% IGEPAL) was 20 to 40 times faster than in air for failure times $>1000 \mathrm{~min}$; however, Scheirs (2009) indicated that the absorption of such agents into the amorphous region had an insignificant effect on other 
mechanical properties of the polymer. Stress cracking that has been affected by sensitising agents is usually known as 'environmental stress cracking'. Oxidising agents (e.g., chlorinated water and oxidising acids) can cause oxidative degradation to the polymer resulting in its embrittlement causing stress cracking of the GMB under very low stresses (Scheirs 2009). This type of stress cracking is known as 'oxidative stress cracking'.

According to Hsuan and Koerner (1998) the degradation of HDPE GMBs may be characterised by three stages: (I) antioxidant depletion; (II) an induction period to the onset of polymer degradation, during which there are no measurable changes in key physical properties; and (III) degradation in the physical properties until failure. The time to nominal failure of the HDPE GMB is taken as the sum of the duration of these three stages. Several investigations have experimentally shown this degradation for GMBs immersed in synthetic MSW leachate (e.g., Rowe et al. 2009, 2010a).

Hsuan and Koerner (1998) defined the time of failure (referred to herein as nominal failure) as the time to when a physical property of interest had dropped to $50 \%$ of its initial value. Recognising that there may be a large difference between the specified properties required and the actual properties of the GMB (especially for stress crack resistance, SCR), Rowe et al. (2009) proposed that that nominal failure be defined as being the time when the property of interest had dropped to $50 \%$ of the specified value (e.g., as indicated in GRI-GM13 (GRI 2012)). From a practical perspective, actual failure of the GMB (i.e., its service life) in a landfill liner may be considered to have occurred when it no longer performs its primary hydraulic function. This would correspond to the time when the GMB liner has sufficient holes to result in excessive leakage (i.e., flow through GMB holes under a hydraulic gradient).

HDPE GMB forming part of a composite liner in a MSW landfill is exposed to leachate from the top, resulting in a chemical exposure to that degrades the GMB (as shown by immersion tests; e.g., Rowe et al. $(2008,2009))$ reducing the material's resistance to tensile strains and cracking. In addition, the GMB is under stress from the overburden pressure of the waste. This induces sustained tensile strains in the GMB (i.e., demand) that can give rise to cracking. The interaction of these two exposure conditions at a given temperature will define how long the GMB liner can perform its function as a hydraulic barrier and remain intact with minimum leakage (i.e., the GMB service life). The effect of these two exposure conditions can be expected to be exacerbated by elevated temperatures.

It may be hypothesised that, if the GMB is subjected to small tensile strains (i.e., low demand), the GMB fails when its resistance drops (e.g., due to chemical exposure) to the level where it can no longer sustain the demand and so failure of the GMB occurs due to oxidative stress cracking. However, if a high demand is sustained long enough (e.g., due to insufficient GMB protection and accelerated by the presence of surfactant), the GMB can experience stress cracking at higher levels of resistance and in this case the failure is largely related to environmental stress cracking.

Studies of HDPE GMBs under simplified loading conditions have demonstrated that a GMB can experience both an increase in tensile strains (Sabir and Brachman 2012) and a reduction (relaxation) in tensile stress (Soong et al. 1994; Lord et al. 1995; Soong 1995; Soong and Koerner 1999) with time when subjected to sustained loading and strain, respectively. Peggs et al. (2005) argued that for GMB liners under field conditions, confinement of the GMB from the underlying soil would prevent its expansion and induce compressive stresses in the GMB that should reduce the residual tensile stresses; however this mechanism may only be expected under fairly ideal and uniform loading conditions.

The literature cited above begs the question: will relaxation be sufficient to prevent cracking of the GMB? If yes, then a GMB that had reached nominal failure as defined earlier should still be performing its primary hydraulic function and should not have reached its end of service life. If no, and the GMB cracked, then lower resistance would be contributed up to the end of the GMB service life as, for cracking to occur, the residual tensile stresses in the GMB were higher than its resistance. This question is investigated in the rest of this paper for one specific set of conditions.

\section{EXPERIMENTAL INVESTIGATION}

Under simulated field conditions, it may be anticipated that the time required to induce failure of a GMB in a brittle manner due to stress cracking, if it were to occur, would take years to decades (or longer) depending on the load conditions and temperature. This is because one can expect that it would take a long time to degrade the GMB to reach nominal failure, even at elevated temperatures, as required to lower the resistance sufficiently for cracking to occur (e.g., Rowe et al. 2009). Since the primary goal of this study was to investigate the potential cracking and rupture under simulated field conditions, a two-phase approach was adopted to facilitate obtaining results in a reasonable period of time. The first phase involved preageing GMBs sheets by immersion in a simulated MSW leachate at $85^{\circ} \mathrm{C}$ for 45 months to reduce the notched constant tensile load (NCTL) SCR (appendix of ASTM D 5397 ) to about $75 \mathrm{~h}$ (i.e., about $25 \%$ of the minimum required by GRI-GM13 (GRI 2012)). In the second phase, the pre-aged samples were installed in specially developed geosynthetic liner longevity simulators (GLLSs) and physical experiments were conducted on the GMBs as part of a composite liner under simulated field conditions at six different temperatures as described below. The synthetic MSW leachate used in this study (Table 1) was selected based on a study by Rowe et al. (2008). Surfactant was a key component of the leachate because it has been shown to accelerate antioxidant depletion (Rowe et al. 2008) and several researchers have observed the presence of surfactant in different MSW landfill leachates (e.g., Maisonneuve et al. 1997; Kjeldsen et al. 2002; Borghi et al. 2003). A relatively high surfactant concentration was used 
Table 1. Composition of synthetic leachate used in current study

\begin{tabular}{|l|c|}
\hline Analyte & Concentration $^{\mathrm{a}}$ \\
\hline $\mathrm{pH}$ & $\sim 6.0$ \\
Eh & $\sim-120$ \\
Aluminium & $<0.01$ \\
Cadmium & $<0.025$ \\
Calcium & 34.2 \\
Cobalt & 0.03 \\
Copper & $<0.2$ \\
Iron & 0.49 \\
Magnesium & 9.1 \\
Manganese & $<0.05$ \\
Nickel & $<0.3$ \\
Potassium & 5.0 \\
Sodium & 19.7 \\
Sulfur & 17.3 \\
Zinc & 0.01 \\
Chloride & 25.5 \\
Sulfate & 28.0 \\
Surfactant & \\
\hline
\end{tabular}

${ }^{a}$ Concentrations in $\mathrm{mg} / \mathrm{l}$ except for $\mathrm{pH}$ (unit less), surfactant $(\mathrm{ml} / \mathrm{l})$, and $\mathrm{Eh}(\mathrm{mV})$

${ }^{b}$ IGEPAL Ca-720.

Tap water is added to surfactant, reducing agent and trace metal solution for leachate preparation.

Trace metal solution is modified from Hrapovic (2001), $1 \mathrm{ml}$ of trace metal solution was added in 1 litre of synthetic leachate.

Reduction potential is adjusted by sodium sulphide nonahydrate $(3 \% \mathrm{w} / \mathrm{v})\left(\mathrm{Na}_{2} \mathrm{~S} \cdot 9 \mathrm{H}_{2} \mathrm{O}\right)$ to maintain $\mathrm{E}_{\mathrm{h}} \sim-120 \mathrm{mV}$ (Rowe et al. 2008). Values reported are the average values for the prepared leachate analysed several times upon leachate preparation.

in this study to be conservative and an industrial surfactant was used to ensure good experimental control in a longterm experiment.

\subsection{Pre-ageing of GMB samples}

The $1.5 \mathrm{~mm}$ thick HDPE GMB used was manufactured on 28 July 2005 by Solmax International (Varennes, Quebec, Canada) and had initial properties as given in Table 2. The GMB was commercially available and met the requirements of GRI-GM13 (GRI 2012). Un-aged samples of the GMB were investigated under a microscope and found to be homogenous without any signs of micro-cavities or defects such as voids, pores, or inclusions.

To allow sufficient sample for the GLLS tests and monitoring of the ageing of the sheets with time, $800 \mathrm{~mm} \times 800 \mathrm{~mm}$ sheets of GMB were immersed in synthetic MSW leachate (Table 1) in a $1 \mathrm{~m}^{3}$ stainless steel tank at $85^{\circ} \mathrm{C}$. The tank had an external pump that circulated the leachate inside the tank to allow uniform leachate flow between the sheets. The synthetic leachate was the same as that previously used by Rowe et al. (2010a, 2010b) and was selected for this study based on the findings of Rowe et al. (2008). The leachate in the bath was regularly changed to prevent the build-up of antioxidant concentrations in the leachate and to accelerate the diffusion of antioxidants from the GMB.

The depletion of antioxidants from the GMB sheets was monitored using both standard OIT (Std-OIT; ASTM D 3895) and high pressure OIT (HP-OIT; ASTM D 5885) tests. The Std-OIT and HP-OIT were depleted to residual values of 1.5 and $80 \mathrm{~min}$, respectively after about 4.5 months (Figure 1a), and hence Stage I was about 4.5 months when immersed in this simulated leachate at $85^{\circ} \mathrm{C}$. The OIT values remained at these residual values for the remainder of the 45 months of ageing. Rowe et al. (2010a) reported the same residual values in leachate immersion tests on the same GMB. This implies that although the antioxidants were not fully depleted, they had reached an inactive level after 4.5 months and were no longer capable of protecting the GMB from subsequent degradation discussed below. The consistent depletion of both HP-OIT and Std-OIT suggest that there were no hindered amine light stabilisers (HALS) in the antioxidant package used in this GMB (Rowe et al. 2010a, 2010b).

Following depletion of antioxidants, polymer degradation mechanisms involve either cross-linking and/or chain scission which cause a change in the molecular weight of the polymer (Hsuan and Koerner 1998; Peacock 2000) that affects the melt index (MI; ASTM D 1238), environmental stress crack resistance (SCR; appendix of ASTM D 5397) and the tensile break strength and strain (ASTM D 6693). Based on the MI, tensile break strength and SCR, polymer degradation commenced after approximately 8.5 months of ageing (Figure 1). Hence, stage II (induction period) was about 4 months under these conditions. Between the onset of stage III after 8.5 months and termination of the pre-aging after 45 months, the SCR and break strength in the cross-machine direction (XD) decreased to about $10 \%$ and $30 \%$ of the initial (virgin GMB) properties, respectively (Figure 1b). The break strength in the machine direction and MI also started to decrease slowly after about 8.5 months incubation (Figure 1c). There was a more rapid drop in machine direction break strength after 40 months of incubation whereas the MI was sustained at around $10 \%$ drop. The slight drop in the MI suggests that the polymer degradation has not involved severe crosslinking that caused an increase in the molecular weight of the polymer or there was a compensating chain scission degradation that did not allow MI to be an effective indicator of degradation (Scheirs 2000). After 45 months of incubation in the simulated leachate at $85^{\circ} \mathrm{C}$, the SCR had reduced to the targeted $75 \mathrm{~h}$ based on SCR tests conducted at $30 \%$ of the yield stress. The degradation evident from the SCR data is probably partly due to the disentanglement of tie molecules (e.g., from swelling of the polymer due to surfactant in the leachate: Kay et al. (2004), Müller (2007) and Scheirs (2009)) which can reduce the SCR, in addition to thermo-oxidative degradation which can reduce both the break strength and SCR.

\subsection{GLLS experiments}

Once the GMB samples had been aged to the target SCR, six were used to construct composite liners in the GLLS for experiments at six different temperatures $(40,55,65$, $70,75,85^{\circ} \mathrm{C}$ ). The stainless steel GLLSs, shown in Figure 2 have been used previously by Rowe et al. (2010b) to examine the depletion of antioxidants under simulated landfill conditions for the same GMB in a composite liner. Specific details on the GLLS design and development 
Table 2. Initial properties of the geomembrane examined

\begin{tabular}{|c|c|c|c|}
\hline Properties & Method & Unit & Value mean $\pm \mathrm{SD}$ \\
\hline $\begin{array}{l}\text { GMB designator } \\
\text { Manufacturing date } \\
\text { Nominal thickness } \\
\text { Resin density } \\
\text { GMB density } \\
\text { Carbon black content } \\
\text { Standard oxidative induction time (Std-OIT) } \\
\text { High-pressure oxidative induction time (HP-OIT) } \\
\text { Crystallinity } \\
\text { Melt index (MI) }\left(21.6 \mathrm{~kg} / 190^{\circ} \mathrm{C}\right) \\
\text { Single point stress-crack } \mathrm{c}^{\mathrm{c}} \text { resistance }\end{array}$ & $\begin{array}{l}- \\
- \\
\text { ASTM D } 5199 \\
\text { ASTM D } 1505 \\
\text { ASTM D } 1505 \\
\text { ASTM D } 4218 \\
\text { ASTM D } 3895 \\
\text { ASTM D } 5885 \\
\text { ASTM E } 794 \\
\text { ASTM D } 1238 \\
\text { ASTM D } 5397\end{array}$ & $\begin{array}{l}- \\
- \\
\mathrm{mm} \\
\mathrm{g} / \mathrm{cm}^{3} \\
\mathrm{~g} / \mathrm{cm}^{3} \\
\% \\
\mathrm{~min} \\
\min \\
\% \\
\mathrm{~g} / 10 \mathrm{~min} \\
\mathrm{~h}\end{array}$ & $\begin{aligned} \text { xA } \\
28 \text { July } 2005 \\
1.5 \\
0.937^{\mathrm{b}} \\
0.947^{\mathrm{b}} \\
2.6^{\mathrm{b}} \\
115 \pm 1.5^{\mathrm{a}} \\
260 \pm 10 \\
47.6 \pm 1.4 \\
14.3 \pm 0.8 \\
720 \pm 130\end{aligned}$ \\
\hline \multicolumn{4}{|l|}{ Tensile properties (machine direction) } \\
\hline $\begin{array}{l}\text { Strength at yield } \\
\text { Strength at break } \\
\text { Strain at yield } \\
\text { Strain at break }\end{array}$ & ASTM D 6693 (Type IV) & $\begin{array}{l}\mathrm{kN} / \mathrm{m} \\
\mathrm{kN} / \mathrm{m} \\
\% \\
\%\end{array}$ & $\begin{array}{l}28.9 \pm 1 \\
47.3 \pm 1.8 \\
22.1 \pm 0.8 \\
822 \pm 30\end{array}$ \\
\hline \multicolumn{4}{|l|}{ Tensile properties (cross-machine direction) } \\
\hline $\begin{array}{l}\text { Strength at yield } \\
\text { Strength at break } \\
\text { Strain at yield } \\
\text { Strain at break }\end{array}$ & ASTM D 6693 (Type IV) & $\begin{array}{l}\mathrm{kN} / \mathrm{m} \\
\mathrm{kN} / \mathrm{m} \\
\% \\
\%\end{array}$ & $\begin{array}{l}30.8 \pm 0.4 \\
46.7 \pm 1.8 \\
17.7 \pm 0.44 \\
874 \pm 46\end{array}$ \\
\hline
\end{tabular}

GMB initial properties are subjected to small changes with time due to storage of the roll at room temperature for long periods and variability of the material within the same roll. Initial values reported in the current study are at the start of the reported experiments (2010) and may be different from initial properties reported previously for the same GMB when roll was received or for studies that will be initiated in future.

The HDPE resin used in manufacturing the GMB is Pétromont (S-7000).

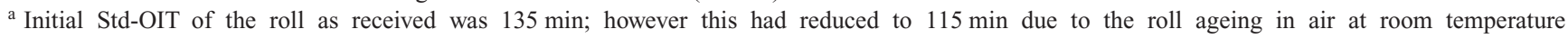
over the 1 year between the date the roll was received and the start of the accelerated ageing for the test reported herein.

b Provided by the GMB manufacturer.

${ }^{\mathrm{c}}$ Mean stress crack resistance ( \pm 1 standard deviation in SCR) at $30 \%$ of the yield stress, $F_{\mathrm{y}}$, in cross machine direction.

have been reported by Brachman et al. (2008). Each GLLS experiment was assembled from bottom to top as follows (Figure 2).

- A $150 \mathrm{~mm}$ thick poorly graded medium sand foundation layer defined by $D_{85}$ (particle diameter at which $85 \%$ of the particles present are finer) $=2 \mathrm{~mm}, D_{50}=0.46 \mathrm{~mm}, D_{10}=0.16 \mathrm{~mm}$, and uniformity coefficient $C_{\mathrm{U}}=D_{60} / D_{10}=3.4$, specific gravity $=2.67$, standard Proctor optimum water content $w_{\mathrm{opt}}=12 \%$, and maximum dry density $\rho_{\max }=1770 \mathrm{~kg} / \mathrm{m}^{3}$ was compacted in six sub-layers at a water content of $7.5 \%$ using standard Proctor energy to a dry density of $1650 \mathrm{~kg} / \mathrm{m}^{3}$.

- A Bentofix NSL GCL (manufactured by TAG Environmental Inc., Barrie Ontario, Canada) with minimum average roll value 'MARV' bentonite mass per unit area of $M_{\mathrm{A}}=3660 \mathrm{~g} / \mathrm{m}^{2}$ (measured $=4490 \pm 400 \mathrm{~g} / \mathrm{m}^{2}$; Hosney and Rowe 2013) was placed on the sand foundation layer. The GCL had a slit-film woven carrier geotextile (GTX; $M_{\mathrm{A}}=$ $\left.105 \mathrm{~g} / \mathrm{m}^{2} \mathrm{MARV}\right)$ and a needle-punched nonwoven cover GTX $\left(M_{\mathrm{A}}=203 \mathrm{~g} / \mathrm{m}^{2}\right.$ MARV). The GCL was hydrated under $20 \mathrm{kPa}$ for 15 days before placing it in the GLLS. Its hydrated thickness at the time it was placed varied between 9 and $12 \mathrm{~mm}$.
- A $0.4 \mathrm{~mm}$ thick circular lead sheet $(500 \mathrm{~mm}$ in diameter) was placed on the GCL for monitoring geomembrane strains (e.g., Witte 1997; Tognon et al. 2000; Gudina and Brachman 2006; Brachman and Gudina 2008a, 2008b; Dickinson and Brachman 2008; Rowe et al. 2010b) and to be used as part of the leak detection system described later.

- The pre-aged GMB was placed over the lead sheet and GCL.

- A Terrafix nonwoven needle-punched GTX protection layer (denoted as 1200R) with measured average thickness of $4.1 \mathrm{~mm}$ (ASTM D 5199), $M_{\mathrm{A}}=$ $560 \pm 15 \mathrm{~g} / \mathrm{m}^{2} \quad$ (ASTM D 5261), grab tensile strength of $1690 \mathrm{~N}$ (ASTM D 4632).

- A $250 \mathrm{~mm}$ thick layer of crushed limestone $\left(D_{85}=55 \mathrm{~mm}, D_{50}=47 \mathrm{~mm}, D_{10}=32 \mathrm{~mm}, C_{\mathrm{U}}=\right.$ $\left.D_{60} / D_{10}=1.4\right)$ primary leachate collection layer (meeting the requirement for MSW landfills in Ontario (MoE 1998)). The gravel was sieved to ensure that the gravel layer was as identical as possible for each experiment. The as-placed gravel had a bulk density of $1500 \mathrm{~kg} / \mathrm{m}^{3}$.

- A $200 \mathrm{~g} / \mathrm{m}^{2}$ nonwoven GTX separator layer and $50 \mathrm{~mm}$ sand cushion was placed over the gravel to protect the rubber bladder membrane from the gravel and provide an even distribution of pressure. 


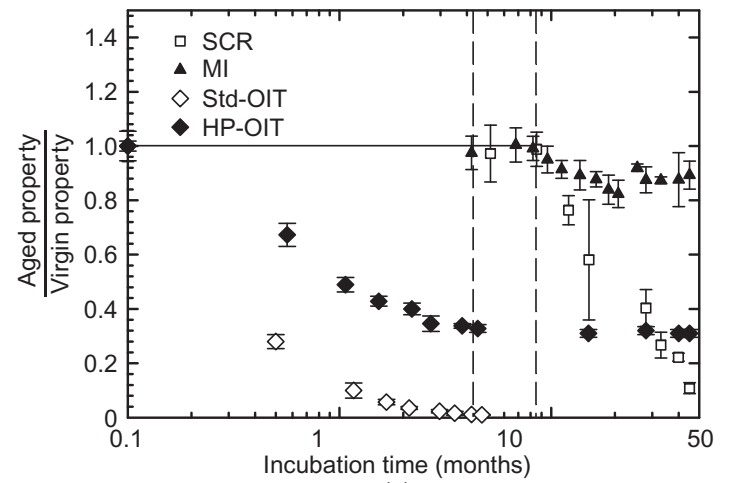

(a)

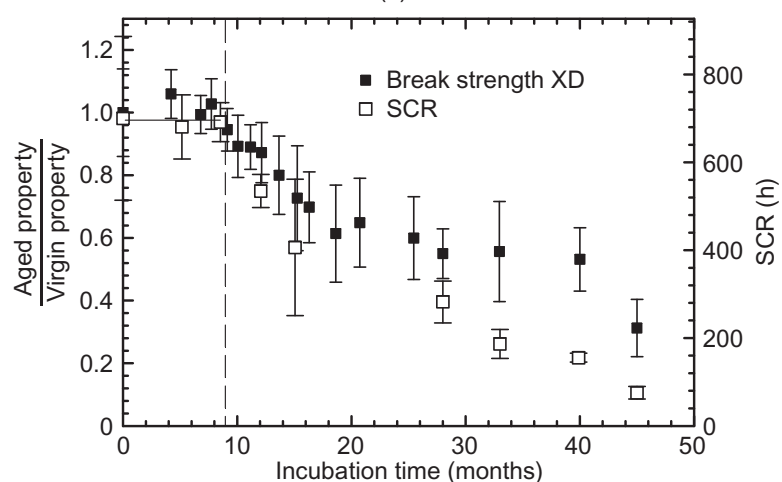

(b)

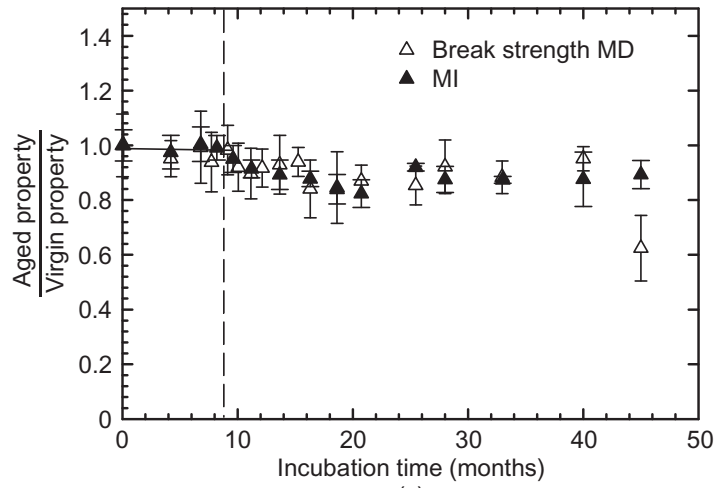

(c)

Figure 1. Index properties of GMB sheets pre-aged by immersion in simulated leachate at $85^{\circ} \mathrm{C}$ for 45 months prior to the GLLS tests showing the variation in (a) Std-OIT, HP-OIT, SCR, and MI with log time (time to the end of Stage II being 8.5 months), (b) break strength in the cross machine (XD) direction and SCR with time; and (c) break strength in the machine direction (MD) and MI with time

- A natural gum rubber bladder that could be inflated with air pressure for applying the desired overburden stresses.

- A steel plate that was bolted to the cell to provide reaction for the applied pressure.

The boundary conditions for each GLLS experiment were as follows (Figure 2).

- A friction treatment comprised of two $0.1 \mathrm{~mm}$ polyethylene sheets lubricated with high-temperature bearing grease and protected from the gravel by concertinaed concentric rings of GMB was applied at the side walls of the cells prior to construction of the simulated liner system to limit the boundary friction on the side wall and ensure a friction angle of less than $5^{\circ}$ (Tognon et al. 1999) and to limit the loss in vertical pressure due to wall friction to less than $5 \%$ (Brachman and Gudina 2002).

- The GLLS were filled with synthetic MSW leachate (Table 1) with a $300 \mathrm{~mm}$ head on top of the liner. The leachate was circulating in the drainage layer throughout each experiment to simulate the continuous flow of leachate in the drainage layer to the leachate collection pipes. An external pump provided a flow of $225 \mathrm{ml} / \mathrm{min}$ in such a manner as to avoid areas of stagnant flow (Brachman et al. 2008). The GMB-cell wall interface was sealed with bentonite around the perimeter of the sample to prevent leakage of leachate below the GMB.

- The GLLSs were wrapped with a self-regulating heating cable and an insulating jacket to minimise heat loss. The cell temperature was monitored using six different thermocouples (two in the subgrade layer and four just beneath the GMB sample) connected to a controller which regulated the temperature to the set point $\left(40,55,65,70,75,85^{\circ} \mathrm{C}\right.$ all $\pm 1^{\circ} \mathrm{C}$; see Brachman et al. 2008) throughout the experiment.

- $250 \mathrm{kPa}$ air pressure (equivalent to $15-20 \mathrm{~m}$ of waste) was applied on the rubber bladder to evenly transmit the pressure to the gravel particles and then the GMB sample once the temperature had reached the desired set point for the experiment.

\subsection{Leak detection sensor}

To allow the identification of the time at which a hydraulically significant crack had formed in the GMB in each experiment, each GLLS had a leak detection system (Figure 3). Since the GLLS cells were made of steel (a good electrical conductor), typical electrical leak detection techniques were not suitable for the GLLS experiments. The specially designed system adopted involved monitoring the resistance between a source electrode in the leachate filled drainage layer above the GMB and the lead sheet below the GMB. With no hole in the GMB, the cell has a total resistance $\left(R_{\text {Cell }}\right.$ in Figure 3$)$ that arises from the resistance provided by the cell walls, the bentonite seal between the GMB and the cell walls, the GMB, GCL and subgrade sand. Once a hydraulically significant crack (i.e., one that would allow leachate to pass through the GMB and contact the lead sheet) occurred in the GMB, there is a new resistor ( $R_{\text {Leak }}$ in Figure 3 ) added to the circuit in parallel with the original cell resistance and hence the total resistance of the cell will change. To detect a leak, there needs to be a considerable difference between $R_{\text {Cell }}$ (which should be as high as possible) and $R_{\text {Leak }}$ (which should be as low as possible) so that the total resistance of the cells is significantly changed before and after the leak. To achieve this objective, the lead sheet was insulated from the GCL below it using a $0.1 \mathrm{~mm}$ polyethylene sheet to minimise the current flowing through the lead sheet to the underlying GCL and subgrade once a leak in the GMB developed. The resistance of the cell was then measured using a multi-channel data acquisition system. The system 


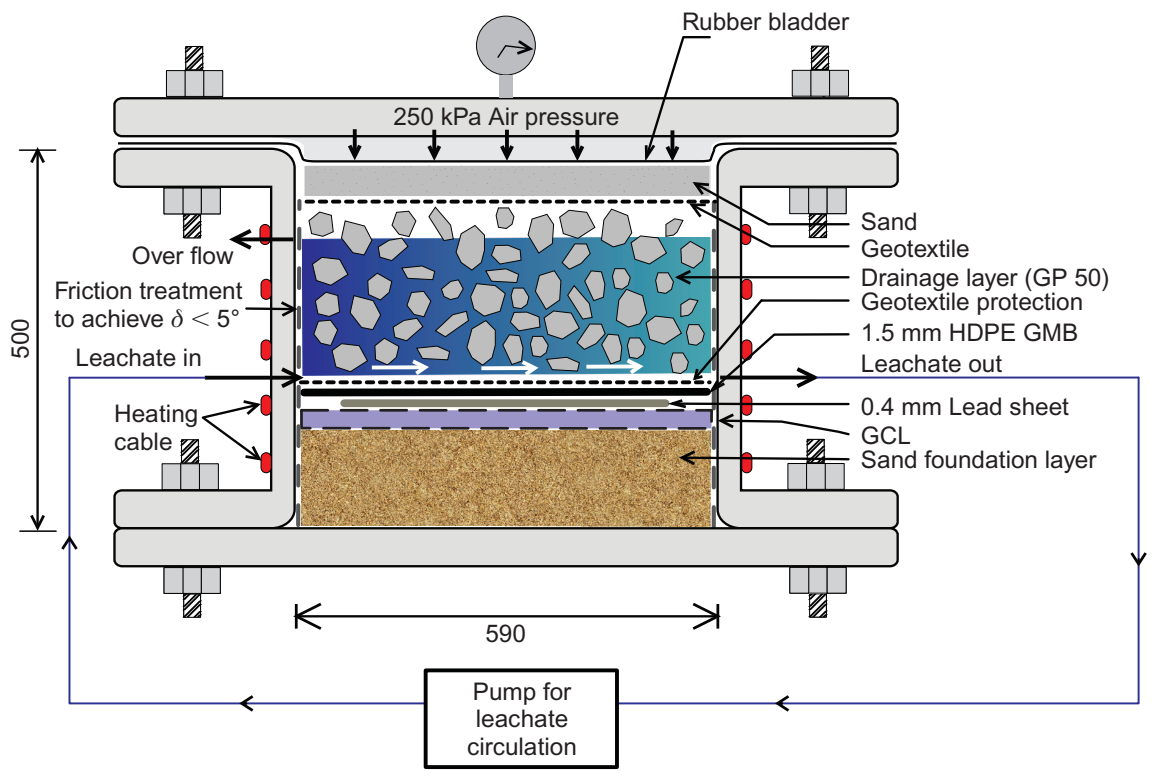

Figure 2. Vertical cross-section through a geosynthetic liner longevity simulator (GLLS, not to scale) showing a typical test configuration and boundary conditions. GMB $=$ geomembrane, GCL $=$ geosynthetic clay liner, GP $50=$ nominal $50 \mathrm{~mm}$ gravel, $\delta=$ friction angle between cell wall and different GLLS layers (dimensions in $\mathbf{m m}$ )

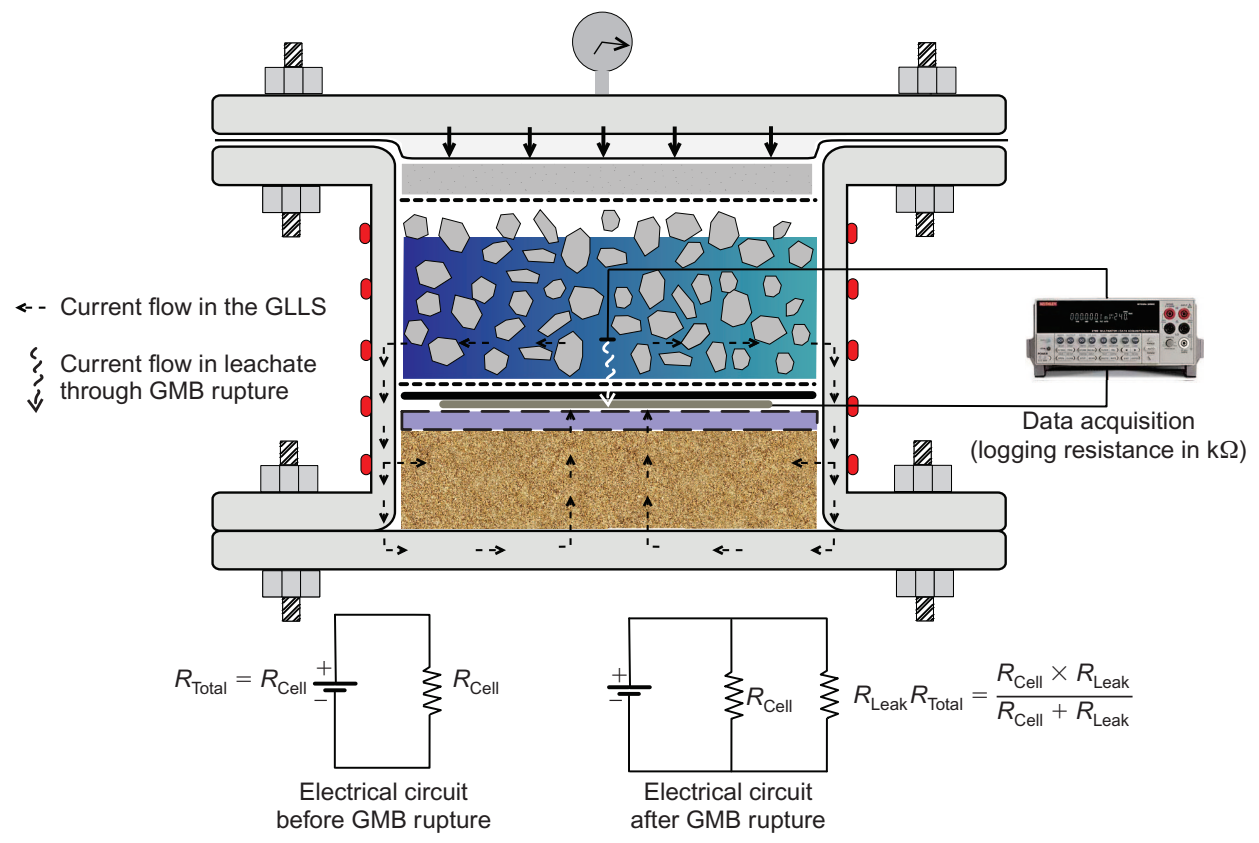

Figure 3. GLLS vertical cross-section showing the leak detection sensor

performance was tested using prototype tests conducted with GMBs having no hole and a $2 \mathrm{~mm}$ diameter predefined hole at different temperatures and pressures prior to the experiments with the pre-aged GMB. The prototyping results showed a significant difference in the resistance prior and after leakage.

\section{RESULTS AND DISCUSSION}

After the GMB had been pre-aged to $75 \mathrm{~h}$ of SCR in the incubation bath at $85^{\circ} \mathrm{C}$, six $\mathrm{GMBs}$ sheets were used to construct composite liner systems as described earlier and GLLS experiments were conducted at 40, 55, 65, 70, 75, $85^{\circ} \mathrm{C}$ with $250 \mathrm{kPa}$ applied vertical pressure. The leak detection resistance readings were recorded every $10 \mathrm{~min}$. after test construction (e.g., Figure 4). Typically, the resistance readings increased to about $100 \mathrm{k} \Omega$ (with some fluctuations) during the period when the cell was being sealed and heated (i.e., about the first $30 \mathrm{~h}$ ). After application of $250 \mathrm{kPa}$ pressure, the resistance dropped to around $30 \mathrm{k} \Omega$ and then increased and stabilised at an average $60 \mathrm{k} \Omega$. The development of a crack which was 


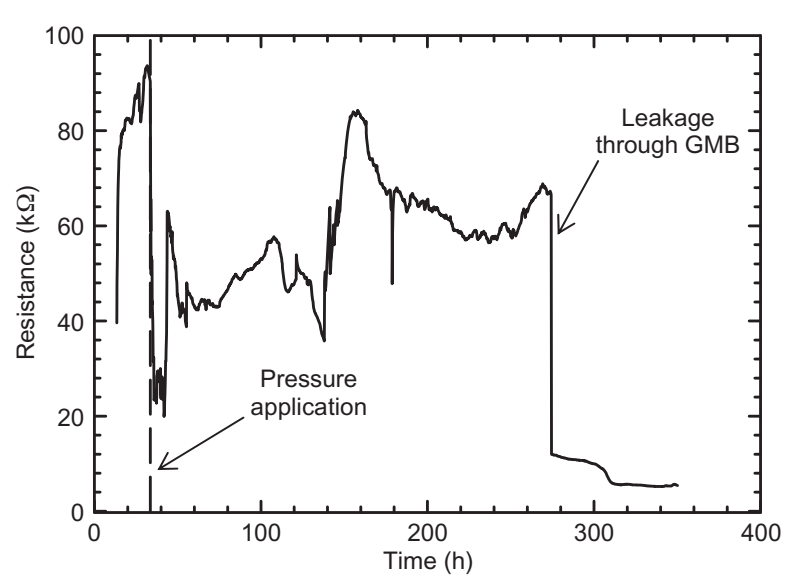

Figure 4. Leak detection sensor reading for the $65^{\circ} \mathrm{C}$ test

sufficient to cause a leak resulted in a sharp and significant drop of readings to less than $5 \mathrm{k} \Omega$ (e.g., at around $300 \mathrm{~h}$ for the test shown in Figure 4). The test was left running for an extra $24 \mathrm{~h}$ after a drop to confirm that the resistance had stabilised at a low value and hence a hydraulically significant crack had developed. At higher temperatures (as discussed later), it is likely that the number of cracks increased in the period between detection of the first crack and termination of the test. Based on the work of Sabir and Brachman (2012), the increase in strain during this $24 \mathrm{~h}$ period is likely to be less than $0.6 \%$ strain at $85^{\circ} \mathrm{C}$ and even smaller at lower temperatures. The test was then terminated and the GLLS cell was dismantled to extract the GMB sample.

Following extraction, the $600 \mathrm{~mm}$ diameter GLLS sample was put on a light table and photographed to show the most significant cracks that had developed within $24 \mathrm{~h}$ of the first hydraulically significant crack causing the reduction in resistance. For example, Figure 5a shows light shining through some of the larger cracks in the GMB tested in the GLLS at $85^{\circ} \mathrm{C}$. Figure 5a understates the severity of the cracking since the width of cracks seen on the light table in Figure 5a are smaller than in the GLLS, due to removal of $250 \mathrm{kPa}$ load and gravel and extraction of the sample from the GLLS. Thus, a tracing was made to record the location and length of all the fully penetrating cracks (ruptures) in the GMB at test termination. Figure $5 \mathrm{~b}$ shows that there were 41 ruptures present in the sample after testing under simulated landfill conditions in the GLLS at $85^{\circ} \mathrm{C}$. These ruptures were distributed over most of the sample. The presence of any ruptures demonstrates that when the SCR is sufficiently low, cracks can initiate and propagate to complete rupture through an HDPE GMB under simulated landfill conditions despite any stress relaxation that may have occurred.

Visual inspection of the samples after termination of the different GLLS experiments showed three distinct stages of crack development (Figure 6): (A) crack initiation, where a small crack is evident on the GMB surface but has no significant depth; (B) partial propagation, where the crack has started to propagate through the GMB but is not evident on the other side; and (C) rupture, where the crack has propagated through the full thickness of the

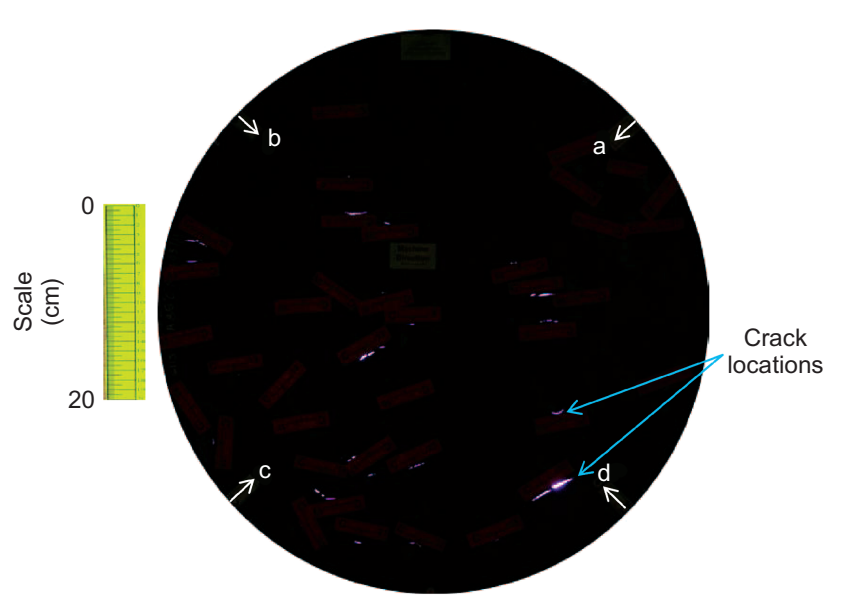

(a)

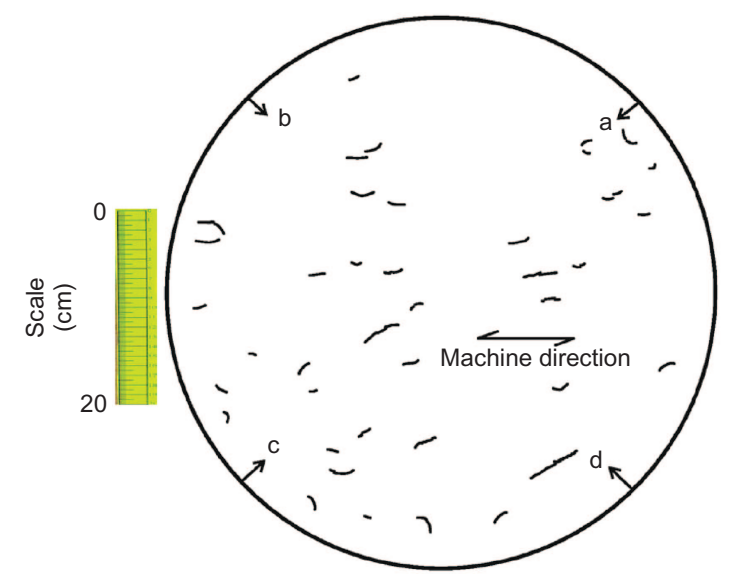

(b)

Figure 5. A $600 \mathrm{~mm}$ diameter GMB sample after failure at $85^{\circ} \mathrm{C}$ in GLLS test. (a) White is light shining through some of the larger cracks; (b) Tracing showing the location of all cracks in the sample at test termination. (a, b, c and $d$ are the locations of the four circulation ports in the GLLS used to orient the GMB sample)

GMB and leakage of fluids can occur through the crack. Figure $7 \mathrm{a}$ shows the location of some of the cracks that developed at termination of the experiment at $70^{\circ} \mathrm{C}$ with cracks in each of the three stages of cracking (as defined above) identified by the tags A (white), B (yellow) and C (red). Of the 48 indentations that were discernible in the test specimen: $6 \%$ had cracks in the initiation stage (A), $23 \%$ had cracks with partial propagation (B), 33\% had fully penetrating cracks (ruptures; C), and the remaining $38 \%$ of the indentations were intact without any apparent crack.

Cracks occurred due to indentations resulting from gravel in the drainage layer. Sometimes there was more than one crack developing at an indentation. For example, Figure 8a shows three such cracks at one indentation where the crack at location $\mathrm{A}$ is at the initiation stage, that at $\mathrm{B}$ is in partial propagation, and that at $\mathrm{C}$ is a fully open crack (rupture). Figure $8 \mathrm{~b}$ shows the deformed shape of the approximately $5 \mathrm{~mm}$ deep indentation and Figure 8c shows the variation of the strains across the indentation as calculated using the method of Tognon et al. (2000). The cracks with partial or complete propagation through the 

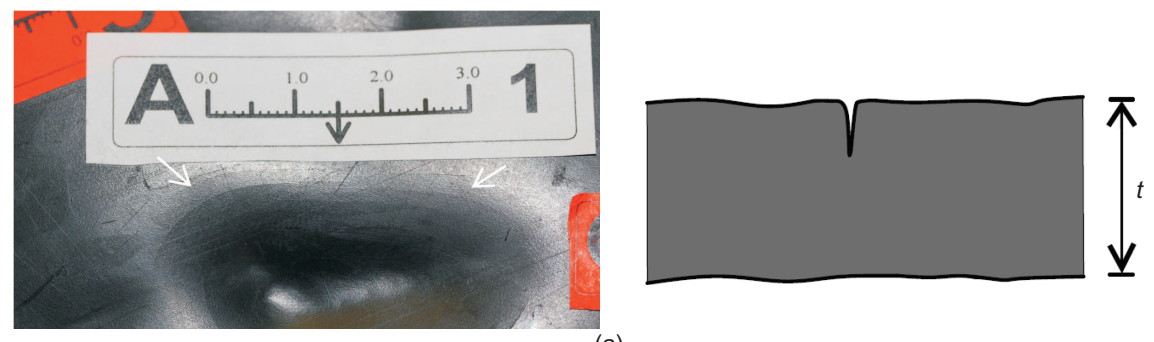

(a)
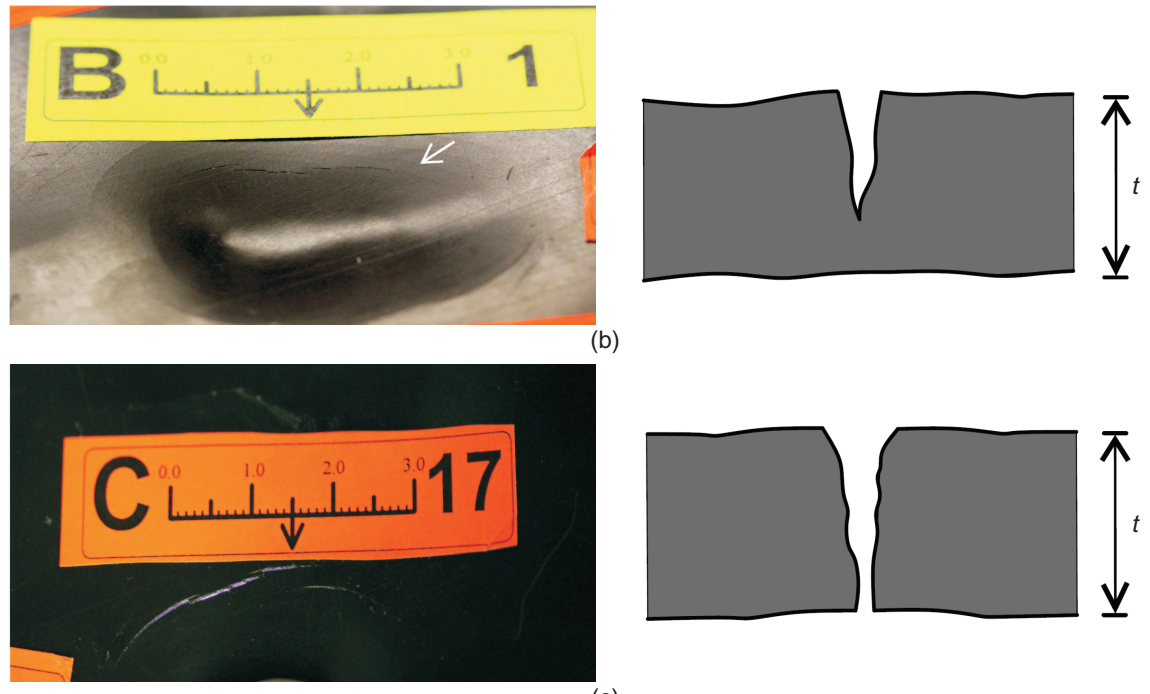

(c)

Figure 6. Plan view photographs and cross-section sketches illustrating: (a) crack initiation, (b) partial propagation and (c) rupture. (See also Figure 8; scale is in $\mathrm{cm}$ )

GMB (locations B and C) were found to occur at the locations of maximum calculated tensile strain (around $13 \%$ ) on both side slopes of the indentation and were generally oriented in the machine direction. At location A, the crack was just initiated at the termination of the experiment and had not yet propagated to rupture. At other locations on the indentation where tensile strains were lower, no cracks had initiated at the time the test was terminated.

\subsection{Orientation of cracks}

Cracks can initiate from a defect at, or close to, the surface of the GMB (Cooney 1964; Lu and Brown 1987; Hsuan 2000). Previous investigators (e.g., Lander 1960; Cooney 1964) have shown that when testing unnotched samples under constant tensile load, there may be considerable scatter in the time to failure due to surface defects. Thus the ASTM D 5397 test method for SCR requires that the specimen be notched (to $20 \%$ of the thickness) to create a stress concentration at the tip of the notch and hence mitigate the effect of surface defects by prescribing the failure location.

For GMBs in a landfill liner or simulated liner (i.e., in the GLLS), it can be expected that there will be some surface scratches. These surface scratches in the GMB liner can cause a reduction in the thickness and hence create regions of stress concentration that could lead to crack initiation. However, a GMB in a landfill liner generally is not in a state of pure tension (as in the SCR test). In many cases, it is loaded by an out-of-plane overburden pressure forcing gravel to indent the liner (Figure 9). The level of indentation will depend on the pressure, gravel, and protection layer but in each case it will induce strains in the GMB that will vary from one location to another (Tognon et al. 2000; Gudina and Brachman 2006; Brachman and Gudina 2008a, 2008b; Dickinson and Brachman 2008; Brachman and Sabir 2010; Gudina and Brachman 2011; Sabir and Brachman 2012). Thus, one might hypothesise that unless there are surface scratches on the GMB, coincidentally, at locations where there are significant tensile strains through the entire thickness of the GMB, they will have little effect on the GMB cracking.

Some surface scratches (from handling the samples during the pre-ageing stage) were observed in the GMB samples tested. Before the start of each GLLS experiment, the top and the bottom surfaces of the $600 \mathrm{~mm}$ pre-aged sample were scanned to identify and record the location of surface scratches. For example, Figure $7 \mathrm{~b}$ shows the location of the scratches in the GMB used in the $70^{\circ} \mathrm{C}$ GLLS experiment together with the location of the ruptures that had developed at the end of the experiment. There was no correlation between the location of the surface scratches in the GMB prior to the GLLS experiment and the rupture locations (i.e., no rupture was initiated from an existing surface scratch) in any of the samples tested (e.g., Figure 7b). This implies that the scratches in the GMBs tested were either not at critical locations and/or not deep enough to cause sufficient stress concentration in the GMB to cause a rupture. Thus while

Geosynthetics International, 2014, 21, No. 1 


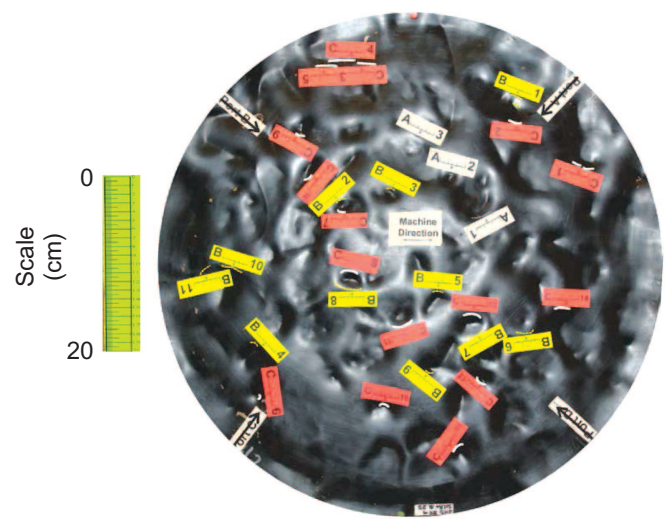

(a)

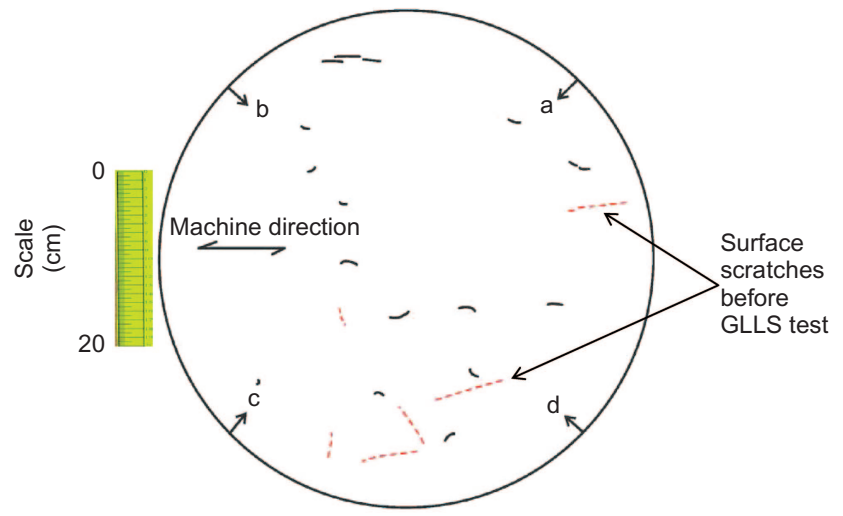

(b)

Figure 7. (a) GMB sample after failure in GLLS at $70^{\circ} \mathrm{C}$ showing the locations where the three stages of crack growth were observed at test termination; (b) Tracing highlighting the rupture locations on the GMB together with surface scratches detected before GLLS test. $a, b, c$ and $d$ are the locations of the four circulation ports in the GLLS used to orient the GMB sample

scratches are not to be encouraged, and in some cases could contribute to cracking, in these experiments they were not a factor.

According to Hsuan (2000), NCTL-SCR samples oriented perpendicular to the machine direction of extruded GMB are expected to be more susceptible to stress cracking (i.e., will have a lower failure time, other things being equal) than those in the machine direction. Other authors have also observed lower resistance to stress cracking across the direction of extrusion (Müller 2007). Consequently, specimens for the NCTL-SCR index test (ASTM D 5397) are taken perpendicular to the machine direction (i.e., in the cross-machine direction) with a notch aligned with the machine direction to ensure a shorter (i.e., more critical) crack propagation time. Hsuan's (2000) finding was confirmed by testing two specimens of the same preaged GMB used in the current study using the ASTM D 5397 SCR test; one taken parallel to the machine direction and the other in the cross-machine direction. With a prescribed notch in the two specimens and under the same tensile load ( $20 \%$ of the initial yield strength), the failure time for the machine direction specimen was $580 \mathrm{~h}$ (with the failure perpendicular to the machine direction) versus
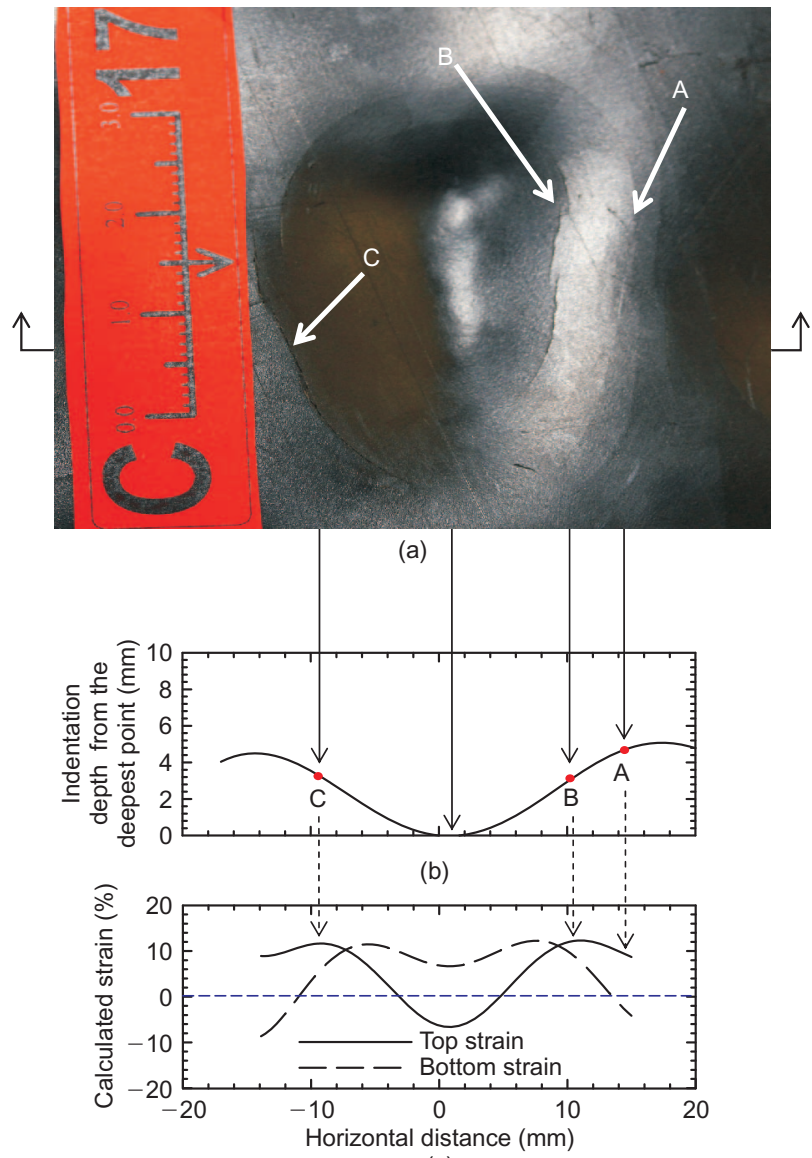

(c)

Figure 8. Portion of a GMB sample from a GLLS test at $75^{\circ} \mathrm{C}$ showing: (a) the three stages of crack growth with crack initiation at $\mathrm{A}$, partial propagation at $\mathrm{B}$, and rupture at $\mathrm{C}$; (b) projected GMB indentation depth together with the calculated tensile strains

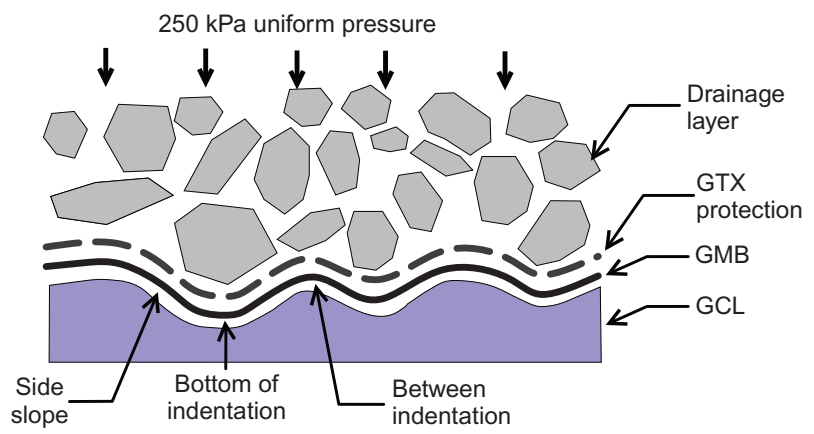

Figure 9. Schematic showing loading of the GMB in simulated field conditions in the GLLS

$430 \mathrm{~h}$ for the cross-machine specimen (with the failure aligned with the machine direction).

An examination of the location and direction of the cracks in all six experiments (e.g., Figures 5b and 7b) indicated that most cracks were aligned parallel, or near parallel, to the machine direction of the GMB sample. The role of the difference in the SCR in the machine and cross-machine directions is especially evident in situations like that observed for the experiment at $55^{\circ} \mathrm{C}$ where, at the time the leak detection system indicated there had been a failure, the GMB had only one crack and it was aligned 
with the machine direction (Figure 10a) with a strain at failure of $8 \%$ in the cross-machine direction (Figure 10b, Section 1-1) but there was no crack at a location where the maximum tensile strain in the machine direction was twice as high (around 16\%, Figure 10b, Section 2-2).

Although the nominal NCTL-SCR (in the crossmachine direction as per appendix of ASTM D 5397) of the GMB used in the current study was $75 \mathrm{~h}$, some variation of the SCR across the pre-aged sheets can be expected. To assess variability in SCR, prior to the GLLS experiments, three specimens were taken from the preaged sheet $(800 \mathrm{~mm} \times 800 \mathrm{~mm})$ at each of four different locations just outside the circumference of the $600 \mathrm{~mm}$
GMB sample (i.e., just outside locations a to $d$ on Figures $5 \mathrm{~b}, 7 \mathrm{~b}$ and $10 \mathrm{a})$. The average SCR values are presented in Table 3 for GMB for the $85^{\circ} \mathrm{C}$ GLLS experiment (Figure 5). The GMB sheet can be considered to have four quadrants (i.e., between $a-b, b-c, c-d$ and $d-a$ in Figure 5) and the average SCR for each quadrant was approximated by averaging the SCR at the two locations on the boundaries of quadrant (Table 3). Quadrant $b-c$ had the highest average NCTL-SCR $(84 \mathrm{~h})$ and 13 cracks while quadrant $\mathrm{b}-\mathrm{a}$ had the lowest average SCR $(75 \mathrm{~h})$ and seven cracks. However, as the difference in the mean SCR were not statistically significant (at 95\% confidence level), this small variation in SCR across the GMB sample had

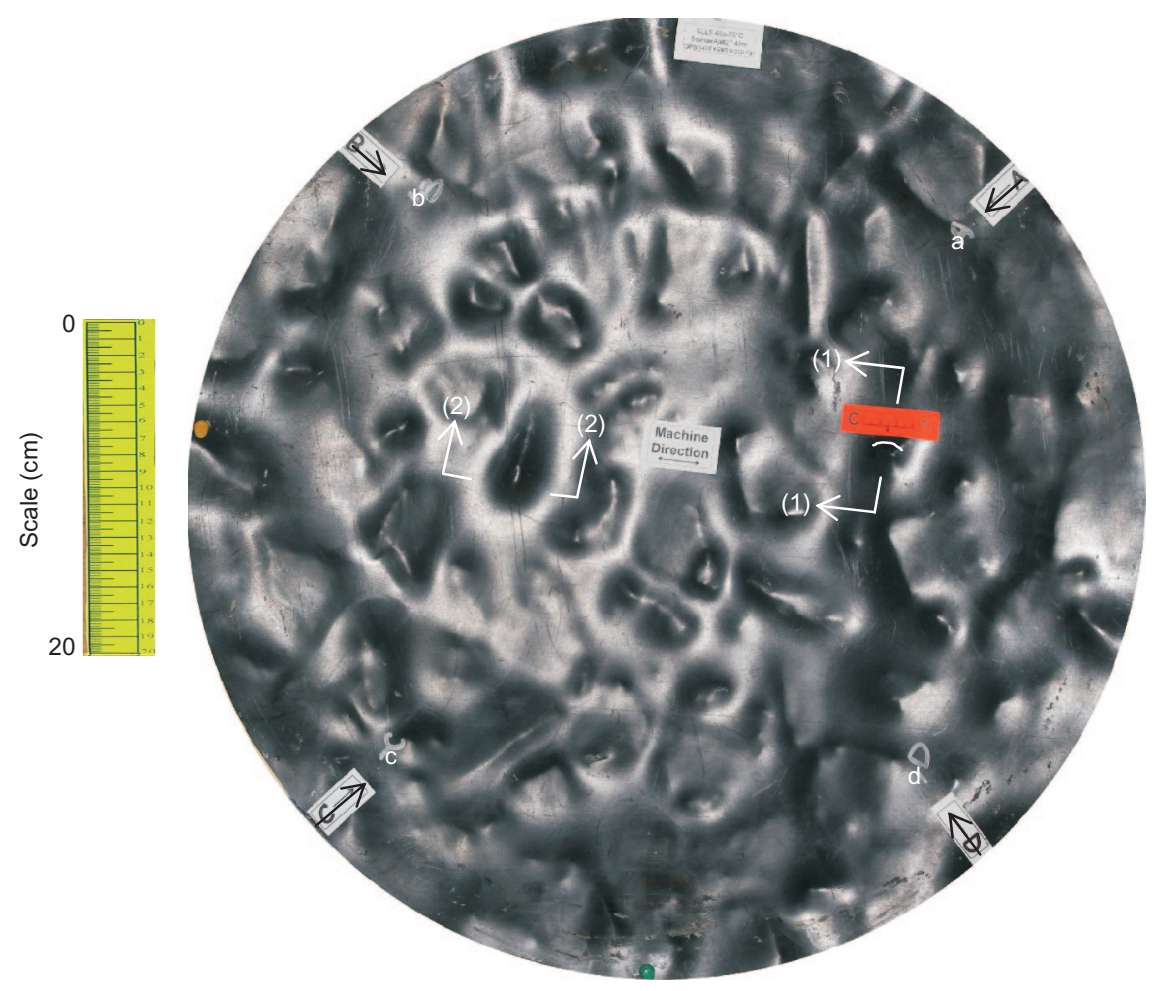

(a)
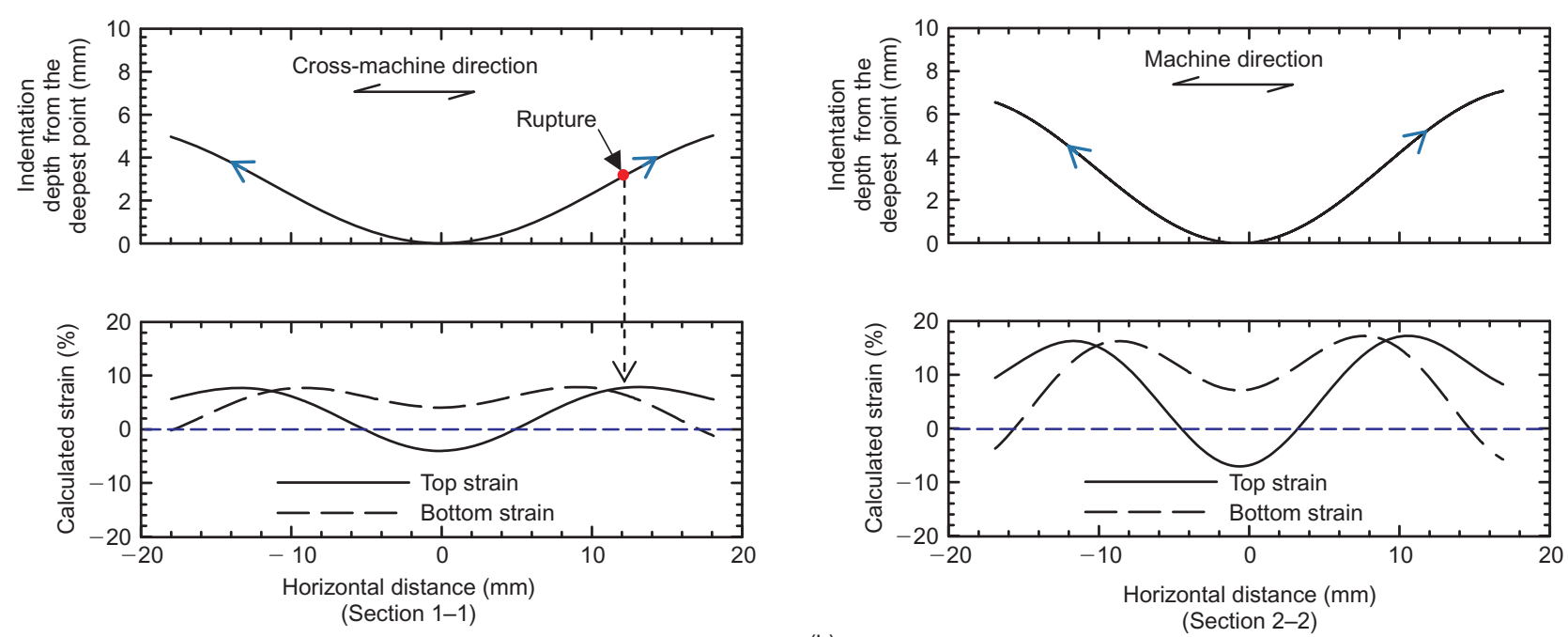

(b)

Figure 10. (a) GMB sample after failure at $55^{\circ} \mathrm{C}$; (b) GMB deformed shape together with the calculated strains for Section 1-1 with a crack in the machine direction and Section 2-2 at the deepest indentation in the GMB without crack although the maximum tensile strain is in the machine direction 
Table 3. Variation of NCTL-SCR (appendix of ASTM D 5397) across GMB sheet after pre-ageing process and before GLLS experiment

\begin{tabular}{|l|c|c|c|c|c|}
\hline GLLS test temperature & Location $^{\mathrm{a}}$ & $\begin{array}{c}\text { SCR (h) } \\
\text { (mean } \pm \text { SD) }\end{array}$ & Quadrant $^{\mathrm{b}}$ & $\begin{array}{c}\text { SCR (h) } \\
(\text { mean } \pm \text { SD) }\end{array}$ & $\begin{array}{c}\text { Number of }^{\mathrm{c}} \\
\text { ruptures }^{\mathrm{d}}\end{array}$ \\
\hline $85^{\circ} \mathrm{C}$ & $\mathrm{a}$ & $78 \pm 33$ & $\mathrm{a}-\mathrm{d}$ & $75 \pm 26$ & 11 \\
& $\mathrm{~b}$ & $72 \pm 16$ & $\mathrm{c}-\mathrm{d}$ & $84 \pm 24$ & 10 \\
& $\mathrm{c}$ & $95 \pm 22$ & $\mathrm{~b}-\mathrm{c}$ & $84 \pm 22$ & 13 \\
Average & $\mathrm{d}$ & $71 \pm 24$ & $\mathrm{a}-\mathrm{b}$ & $75 \pm 24$ & 7 \\
\hline
\end{tabular}

a Three specimens taken from the pre-aged sheets each at four locations just outside the circular GLLS samples used in the GLLS experiment (a, b, c and d shown on Figure 5b) and were tested for NCTL-SCR.

b The GLLS circular sample was divided into the four quadrants noted and the SCR for each sector was calculated by averaging the SCR values obtained for the sample taken at the locations either side of the quadrant (e.g., average SCR for sector a- $d$ is the average for the three specimens at location a and the three specimens at location d).

${ }^{c}$ Average SCR calculated for each quadrant.

d Number of fully penetrating cracks (ruptures) observed for quadrant.

no effect on the crack formation across this or any of the other $600 \mathrm{~mm}$ diameter GMB samples. The difference between the SCR of the corner samples from this sheet and the target SCR of $75 \mathrm{~h}$ was also not statistically significant (at 95\% confidence level).

\subsection{Effect of temperature on GMB cracking}

Temperature is known to affect the failure time for polyethylene (PE) in hot water pipes subjected to internal pressure (e.g., Viebke et al. 1994) and for notched specimens under uniaxial constant tensile load (e.g., Lu and Brown 1990; Brown and Lu 1995), however the authors are not aware of any studies of the effect of temperature on failure (cracking) of GMB bottom liners under field or simulated field conditions. The present study begins to address this shortcoming.

Following detection of the first leak, a GLLS experiment was continued for $24 \mathrm{~h}$ to confirm that rupture had indeed occurred before it was terminated. Thus there was a 24-h period for additional cracks to form after the initial rupture(s) that caused the leak detected by the leak detection system. It might be hypothesised that the development of additional cracks in the 24-h period would be temperature dependent. Indeed this appears to be the case from Figure 11, which shows the number of fully penetrating cracks (ruptures) in a GMB sample following the GLLS experiments at different temperatures. The greatest number of ruptures at termination was at $85^{\circ} \mathrm{C}$ (41 ruptures per $600 \mathrm{~mm}$ diameter sample) versus one rupture at $55^{\circ} \mathrm{C}$. The data suggest that the failure is progressive and accelerated by elevated temperature. At $85^{\circ} \mathrm{C}$, the cracking had spread over the GMB sample and was observed at almost every significant gravel indentation (which had depths ranging from 2.9 to $5.2 \mathrm{~mm}$ ) within $24 \mathrm{~h}$ of the first rupture being detected. A similar effect appeared to be developing but at a slower rate at lower temperatures. The 41 ruptures in the $600 \mathrm{~mm}$ sample at $85^{\circ} \mathrm{C}$ GLLS corresponds to $\sim 1.5$ million holes per hectare while the single rupture at $55^{\circ} \mathrm{C}$ corresponds to about 35000 holes per hectare. In either case, the GMB can be considered to have failed in that it would be unlikely to continue to perform its primary function as a

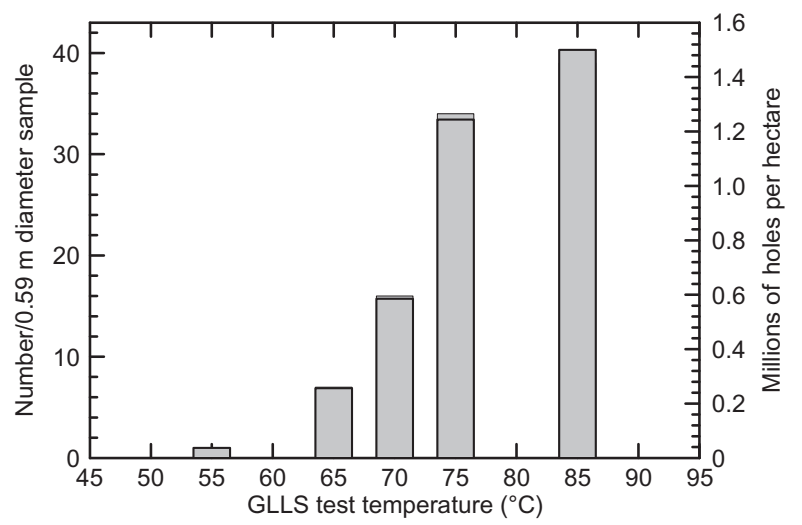

Figure 11. Number of ruptures formed in GLLS after test termination for samples tested at different temperatures

hydraulic barrier layer once this level of cracking had developed.

The time to the initial (detected) rupture was highly dependent on temperature (Figure 12a). For these samples pre-aged to $75 \mathrm{~h} \mathrm{SCR}$, it only took $24 \mathrm{~h}$ (1 day) from load application on the sample in the GLLS experiment to failure at $85^{\circ} \mathrm{C}$ but this increased to $770 \mathrm{~h}$ (32 days) at $55^{\circ} \mathrm{C}$ (Table 4). These failure times do not reflect the service life of the GMB (but rather the relative time it takes for cracking of samples pre-aged to $75 \mathrm{~h}$ SCR); however, they do show the significant dependence of rupture time on temperature.

The data presented in Figure 12a relating temperature to failure time were fitted with an exponential function (with $R^{2}=0.99$ ). This can be useful in interpolation of likely failure times for temperatures other than those used in the experiments (i.e., between 55 and $85^{\circ} \mathrm{C}$ ). While liner temperatures of around $55^{\circ} \mathrm{C}$ have been encountered in a number of field applications (Rowe 2012), they may more typically be expected to be in the $30 \sim 40^{\circ} \mathrm{C}$ for normal landfill operations (Rowe 2005, 2012). Thus, a predictive technique is required to extrapolate failure times for site-specific temperatures below $55^{\circ} \mathrm{C}$ as conducting laboratory experiments at such low temperatures would take a long time. Arrhenius modelling is the 


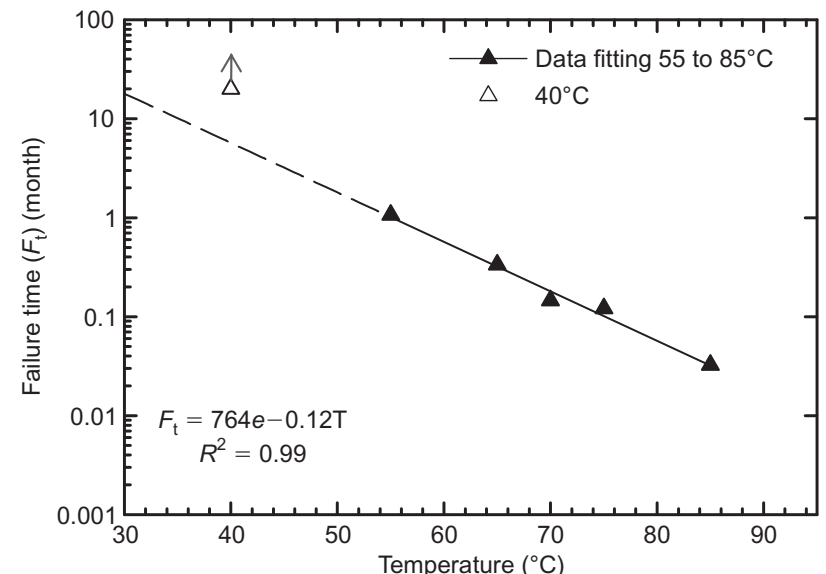

(a)

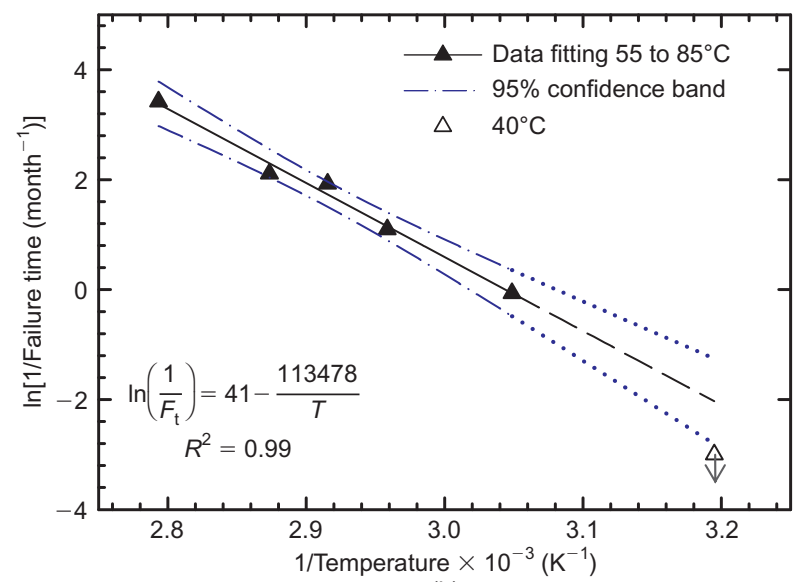

(b)

Figure 12. Variation of time to failure, $F_{t}$ in GLLS test with temperature; (a) logarithmic scale and temperature in Celsius; (b) natural logarithmic of $1 / F_{t}$ versus $1 /$ temperature in Kelvin (Arrhenius plot). Failure at $40^{\circ} \mathrm{C}$ had not yet occurred at the time of writing and the arrow is to indicate that the failure time is longer than implied by the data point shown which represents the time of writing

Table 4. Failure time of GMB pre-aged to about $75 \mathrm{~h}$ SCR in GLLS test (rounded to 2 significant digits)

\begin{tabular}{|l|c|c|}
\hline Temperature $\left({ }^{\circ} \mathrm{C}\right)$ & Failure time $\left(\mathrm{h}^{\mathrm{a}}\right)$ & Failure time $\left(\right.$ days $\left.^{\mathrm{a}}\right)$ \\
\hline 85 & 24 & 1 \\
75 & 87 & 3.6 \\
70 & 100 & 4.2 \\
65 & 240 & 10 \\
55 & 770 & 38 \\
\hline
\end{tabular}

a Time from application of test boundary conditions (GMB temperature and pressure) until cracks were detected by the leak sensor.

predictive technique most widely used for polymer degradation based on a time-temperature superposition (tTS) principle (Koerner et al. 1992). Arrhenius modelling has been widely used to extrapolate the time for antioxidant depletion observed in accelerated laboratory tests at sitespecific temperatures (e.g., Hsuan and Koerner 1998; Sangam and Rowe 2002; Müller and Jacob 2003; Gulec et al. 2004; Rimal et al. 2004; Rowe et al. 2008, 2009, 2010a, 2010b; Rowe and Rimal 2008a, 2008b; Abdelaal et al. 2011, 2012). Koerner et al. (1992) demonstrated the validity of application of Arrhenius modelling for modelling creep and stress relaxation for semi-crystalline polymers. Soong et al. (1994) used tTS for stress relaxation predictions while Sabir and Brachman (2012) used tTS to extrapolate GMB tensile strains under simulated field conditions using a multi component system having a GMB on top of clay with a geotextile protection layer for $160 \mathrm{~mm}$ diameter GMB sample tested under single machined steel probe intended to simulate a gravel particle. However, no work has been done to quantify failure time of the GMB liner under simulated field conditions similar to the one presented in the current study and hence the appropriateness of the implementation of tTS techniques such as the Arrhenius modelling is investigated.

With respect to the failure time-temperature relationship for GMB in Stage III of the three stages of degradation, the Arrhenius equation can be written as:

$$
\frac{1}{F_{\mathrm{t}}}=A \mathrm{e}^{-\left(E_{\mathrm{a}} /(R T)\right)}
$$

where $F_{\mathrm{t}}$ is the time to failure in GLLS (month), $T$ is the GLLS test temperature $(\mathrm{K}), E_{\mathrm{a}}$ is the activation energy $\left(\mathrm{J} \cdot \mathrm{mol}^{-1}\right), A$ is an empirical constant $\left(\mathrm{month}^{-1}\right), R$ is the universal gas constant $\left(8.314 \mathrm{~J} \cdot \mathrm{mol}^{-1} \cdot \mathrm{K}^{-1}\right)$. Taking the natural logarithm on both sides of Equation 1 gives:

$$
\ln \left(\frac{1}{F_{\mathrm{t}}}\right)=\ln (A)-\left(\frac{E_{\mathrm{a}}}{R}\right)\left(\frac{1}{T}\right)
$$

Figure $12 \mathrm{~b}$ shows that the experimental data obtained from the GLLS experiments at five elevated temperatures $\left(55,65,70,75\right.$ and $\left.85^{\circ} \mathrm{C}\right)$ follows a linear relationship when plotted as $\ln \left(1 / F_{\mathrm{t}}\right)$ versus $1 / T$ with a coefficient of determination of 0.99 . This linear best fit suggests that the nature of the relationship between rupture of the GMB and temperature did not change over the test temperature range from 55 to $85^{\circ} \mathrm{C}$. The slope of the regression curve $\left(E_{\mathrm{a}} / R\right)$ gives an activation energy of $112 \mathrm{~kJ} / \mathrm{mol}$ while the $95 \%$ confidence limits gives $90<E_{\mathrm{a}}<134 \mathrm{~kJ} / \mathrm{mol}$. Equation 2 can be used to extrapolate the failure time (for similar test conditions) to lower temperatures than presented. For example, the Arrhenius relationship presented in Figure $12 \mathrm{~b}$ predicts a failure time of about 8 months at $40^{\circ} \mathrm{C}$ based on the currently presented activation energy and varies between 4 to 16 months based on the $95 \%$ confidence limits activation energy (as compared to about 7 months for exponential fit to the data in Figure 12a).

To test this prediction, a GLLS test is being conducted at $40^{\circ} \mathrm{C}$. At the time of writing it has been running for 20 months $(>15000 \mathrm{~h})$ and failure has not yet been detected. This exceeds the predicted time and falls outside the $95 \%$ confidence level band of the Arrhenius plot shown in Figure 12b. Müller (2007) indicated that for notched GMB specimen under constant strain at $50^{\circ} \mathrm{C}$ in the bent strip test (ASTM D 1693), modern GMBs do not exhibit failure even after thousands of hours of testing. The present experiments for a GMB in a composite liner configuration have demonstrated in this paper that GMB cracking can occur in the GLLS at $55^{\circ} \mathrm{C}$. However, the fact that at $40^{\circ} \mathrm{C}$ 
failure did not occur at a time consistent with the failures at a higher temperature suggests that conditions may change (for the better) below $55^{\circ} \mathrm{C}$ with a probable change in the slope of the Arrhenius plot for the data below $55^{\circ} \mathrm{C}$. Thus, while Arrhenius modelling was an appropriate technique for extrapolation of rupture time for temperatures between 55 and $85^{\circ} \mathrm{C}$ for the conditions examined, it may not capture the stress crack behaviour of the GMB at temperatures below $55^{\circ} \mathrm{C}$ with a single activation energy. The findings from the bent strip results reported by Müller (2007) and the delay in the rupture time at $40^{\circ} \mathrm{C}$ in the current experiments suggests that there may be a temperature threshold which is a characteristic of GMB performance when incubated at different temperatures but, in the current study, this could also be influenced by other factors due to the GMB being in a fully simulated barrier system. The test at $40^{\circ} \mathrm{C}$ is ongoing and longer monitoring is required to determine whether, and if so when, cracking will occur at this temperature. Based on the present data at $40^{\circ} \mathrm{C}$ the predictions based on the relationships presented (based on $55-85^{\circ} \mathrm{C}$ data; Figure $12 \mathrm{~b}$ ) are conservative at a temperature of $40^{\circ} \mathrm{C}$.

Unlike the activation energy corresponding to the Arrhenius relationship developed for GMBs in immersion tests, such as those cited above, the activation energy presented in the current study, does not reflect a fundamental characteristic of the reaction rate of a single temperature-dependent property of the polymer (such as antioxidant depletion, etc.) as the GMB tested is a part of a composite liner system. The rupture of the GMB liner forming part of a composite liner tested under field conditions (simulated or actual) is dependent on the interactions between different components of the composite liner system including: (a) creep in the geotextile protection layer, GMB liner, GCL, and subgrade layer; (b) stress relaxation in the GMB and (c) SCR of the GMB, which are all temperature dependent.

GMB cracks were generally initiated at the location of maximum tensile strains as calculated using Tognon et al. (2000)'s method, especially when the cracks occurred in the cross-machine direction. These cracks commonly occurred on the side slopes of indentations. For the indentations where strains were calculated (see notes to Table 5), the average of the maximum tensile strain of the fully penetrating cracks (ruptures) was approximately 8\% for the GLLS at $55^{\circ} \mathrm{C}$ while at $85^{\circ} \mathrm{C}$ it was $12 \%$ (Table 5). The average of the maximum tensile strains of ruptures for each GLLS increased linearly with increasing temperature (Figure 13), although the differences in the average strains at intermediate temperatures were not statistically significant (at the 95\% confidence level). The variations in strains at different indentations where cracks formed for the same GLLS experiment is to be expected given the variation in the size and shape of the gravel contacts. This variability was also observed and quantified by Brachman and Gudina (2008a) based on many replicate GLLS experiments at room temperature using the same gravel.

A complicating factor affecting strains is the compensating effect of creep rate and time to failure at different temperatures. The GMB creep rate decreases with the decreasing temperature (Sabir and Brachman 2012) which would tend to give lower strains at lower temperatures (other things being equal). However the time to failure increases with deceasing temperature and hence there is much more time for creep strain to develop in a test at a low temperature than at high temperature (e.g., about 33 days at $55^{\circ} \mathrm{C}$ versus 2 days at $85^{\circ} \mathrm{C}$, including the additional day after rupture before the test was terminated and the strains were evaluated). Figure 14 presents the

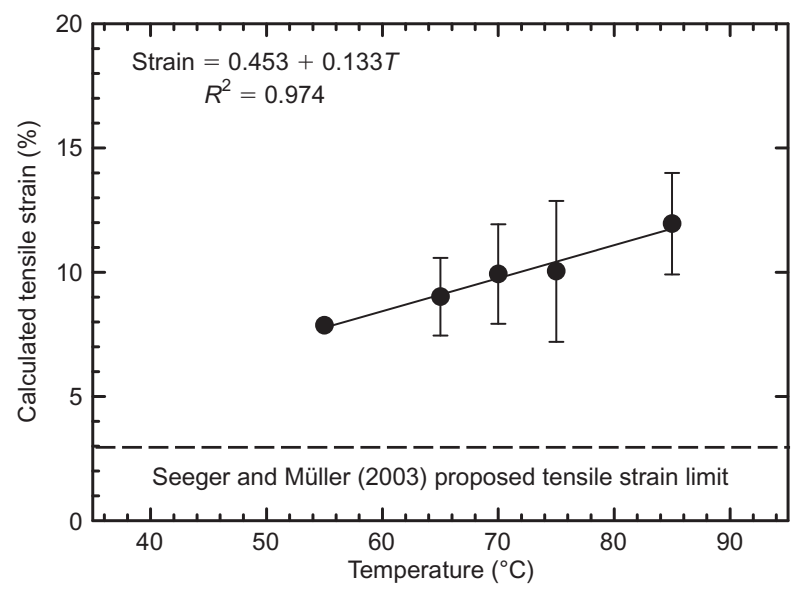

Figure 13. Maximum strains at rupture locations (and standard deviation when there was more than one rupture) for each GLLS test with different GMB temperature

Table 5. Tensile strains at rupture locations after failure in GLLS test

\begin{tabular}{|c|c|c|c|c|c|}
\hline \multirow[t]{2}{*}{ Temperature $\left({ }^{\circ} \mathrm{C}\right)$} & \multirow{2}{*}{$\begin{array}{c}\text { Total number of } \\
\text { ruptures }\end{array}$} & \multirow{2}{*}{$\begin{array}{l}\text { Number of scanned } \\
\text { indentations with ruptures }\end{array}$} & \multicolumn{3}{|c|}{ Tensile strain ${ }^{\mathrm{a}}$ in the GMB at rupture locations (\%) } \\
\hline & & & Highest strain & Lowest strain & Mean $\pm \mathrm{SD}$ \\
\hline 85 & 41 & 9 & 15.3 & 9.0 & $12 \pm 2.0$ \\
\hline 75 & 34 & 13 & 15.7 & 6.0 & $10.0 \pm 2.9$ \\
\hline 70 & 16 & 6 & 11.8 & 7.0 & $9.9 \pm 2.0$ \\
\hline 65 & 7 & 4 & 10.8 & 7.4 & $9.0 \pm 1.5$ \\
\hline 55 & 1 & 1 & 7.9 & 7.9 & 7.9 \\
\hline
\end{tabular}

a Strains at indentations with ruptures based on deformations recorded in lead sheets which were scanned. The strains were calculated using the method of Tognon et al. (2000).

${ }^{b}$ The lead sheets only extended below part of the GMB and hence the strains could only be calculated for those ruptures above the lead sheet. For the experiments at 70,75 and $85^{\circ} \mathrm{C}$, most of the ruptures were outside the lead sheet (e.g., at $85^{\circ} \mathrm{C}$ only about $22^{\circ}$ of the ruptures were at locations where they could be scanned) and hence the maximum and minimum strains could be larger and smaller than those indicated here. 


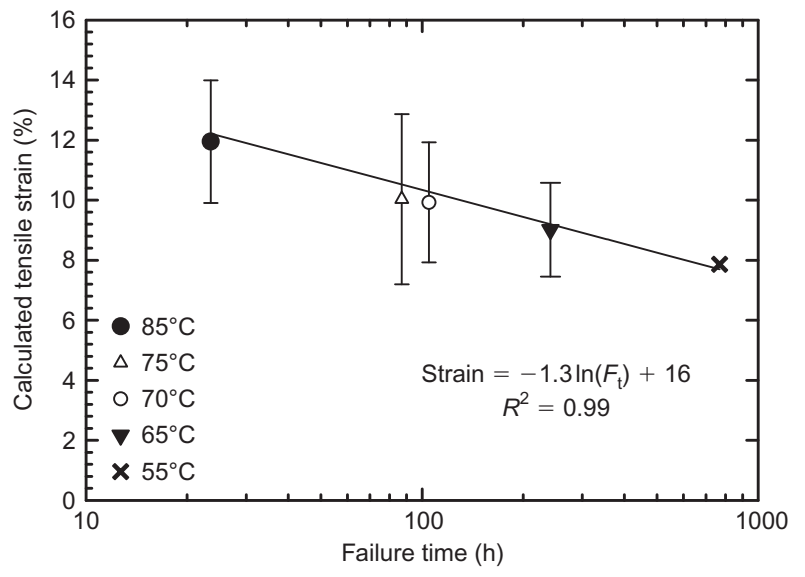

Figure 14. Variation of maximum strains at rupture locations (and standard deviation when there was more than one rupture) with failure time in GLLS at different temperatures

relationship between average strains at the ruptures where the strain was monitored and the logarithm of failure time for the five GLLS experiments where a rupture was observed. While the average and maximum strains are of interest since they correspond to hydraulically significant cracks (i.e., ones that allowed enough leachate through the GMB to trigger the leak detection system), the strain at which a fully penetrating crack first develops is not known. It is known that at a strain of $8 \%$, the one rupture in the GLLS at $55^{\circ} \mathrm{C}$ was hydraulically significant. However there were strains lower than this corresponding to ruptures in $75 \%$ of the other experiments and a rupture was observed at a strain as low as $6 \%$ for the experiment at $75^{\circ} \mathrm{C}$ (Table 5).

Based on the empirical relationship in Figure 13, the average tensile strains at rupture for the conditions examined can be interpolated at different temperatures (Table 6). The fact that the time to failure at $40^{\circ} \mathrm{C}$ is longer than predicted based on the Arrhenius plot of temperatures of $55-85^{\circ} \mathrm{C}$ may mean that at $40^{\circ} \mathrm{C}$ the failure strain also does not follow the trend observed in Figure 13 between 55 and $85^{\circ} \mathrm{C}$. This is under continued investigation and it may be some/many years before the time to failure and failure strain (if it does fail) are known. The longer it takes to resolve the issue, the better the performance of the GMB is likely to be in the field.
The relationship between average strains at the ruptures where the strain was monitored and the logarithm of failure time at different temperatures (Figure 14) shows that the failure times were relatively short and occurred at higher average tensile strains in the GMB at high temperature while at lower temperatures the failure times were much longer but occurred at lower average tensile strains.

It can be hypothesised that, after load application, initial tensile strains are developed in the GMB in response to the deformation/indentations caused by the interaction between the gravel and the composite liner system (i.e., GTX protection layer, GMB, GCL and underlying sand). These strains in the GMB will have associated initial tensile stresses. It can also be expected that the creep rate of the composite liner will be greater at higher temperatures than at lower temperatures, resulting in higher tensile strains developing in the GMB at higher temperatures (other things being equal). Creep in the system may be accompanied by stress relaxation in the GMB that could reduce the tensile stresses with time (with rates depending on the GMB temperature) to residual values (Soong et al. 1994). However, studies suggest that, after stress relaxation, the residual tensile stresses (as a percentage of the initial stresses) are higher for GMBs at higher temperature (Soong et al. 1994; Soong 1995; Soong and Koerner 1999). If this is the case, then higher temperatures will result in both faster rates of creep and stress relaxation occurring together, resulting in both high tensile strains and high residual tensile stresses which, in turn, will result in faster rupture of the GMB than at lower temperatures (other things being equal). At lower temperatures, the stress relaxation is slower but so too is the residual tensile stress and hence it may be expected that it will take longer than at higher temperature for the initiation of cracking under the lower sustained tensile stresses. In addition, $\mathrm{Lu}$ and Brown (1990) showed that under similar constant tensile load, the crack propagation time is shorter for higher temperatures, implying that the polymeric resistance to slow crack growth is reduced with increasing temperature (other things being equal). This reduction in the resistance of the GMB to slow crack growth would also contribute to a reduction of the GMB failure time with increasing temperature. The extent to which these different factors contribute to the final result is unknown,

Table 6. Predicted time to failure and strain at failure at different temperatures (rounded to two significant digits)

\begin{tabular}{|l|c|c|c|c|}
\hline \multirow{2}{*}{ Temperature $\left({ }^{\circ} \mathrm{C}\right)$} & \multicolumn{2}{|c|}{ Predicted failure time (days) } & \multirow{2}{*}{$\begin{array}{c}\text { Predicted average strain at } \\
\text { failure }{ }^{\mathrm{d}}(\%)\end{array}$} \\
\cline { 2 - 5 } & $E_{\mathrm{a}}=112 \mathrm{~kJ} / \mathrm{mol}^{\mathrm{a}}$ & $E_{\mathrm{a}}=90 \mathrm{~kJ} / \mathrm{mol}^{\mathrm{b}}$ & $E_{\mathrm{a}}=134 \mathrm{~kJ} / \mathrm{mol}^{\mathrm{c}}$ & 14 \\
\hline 90 & 0.6 & 0.9 & 0.4 & 11 \\
80 & 1.7 & 2.2 & 5.4 & 9.6 \\
70 & 5.3 & 5.3 & 22 & 8.5 \\
60 & 17 & 38 & 97 & 7.5 \\
50 & 60 & 38 & 5.3 & 14 \\
\hline
\end{tabular}

${ }^{a}$ Calculated from the Arrhenius equation (Equation 2) presented in Figure $12 \mathrm{~b}$ (best fit for $55,65,70,75,85^{\circ} \mathrm{C}$ data).

${ }^{\mathrm{b}}$ Calculated based on lower limit activation energy of the $95 \%$ confidence level.

${ }^{c}$ Calculated based on upper limit activation energy of the $95 \%$ confidence level.

${ }^{\mathrm{d}}$ Calculated strain at failure based on the empirical equation presented in Figure 13 with strains rounded up to the nearest $0.5 \%$. 
but the results in Figure 14 certainly suggest that cracking will occur at all temperatures (within the examined temperature range) but that it will take longer and will occur at a lower tensile strain at lower temperatures than at higher temperatures.

The previous results show that the geotextile protection layer used, which is not untypical of that used in North America, was sufficient to protect the GMB from shortterm punctures but allowed the development of indentations with resultant tensile strains sufficient to cause stress cracking of the aged GMB examined. Cracks were observed at strains as low as $6 \%$, highlighting the need to prevent indentations that cause tensile strains of this magnitude by ensuring an appropriate protection layer between the drainage gravel and GMB. Various types of protection layer have been used to limit local tensile strains in GMBs used in landfills including: thick soil layers (Seeger and Müller 1996, 2003; Gudina and Brachman 2006; Dickinson and Brachman 2008; Rowe et al. 2013); very thick nonwoven needle-punched geotextiles (Seeger and Müller 1996; Zanzinger 1999; Gudina and Brachman 2006; Brachman and Gudina 2008a; Koerner et al. 2010); multi-layered geotextiles composites (Brachman and Sabir 2013); various sand-filled geocomposites (Saathoff and Sehrbrock 1994; Zanzinger 1999; Tognon et al. 2000; Dickinson and Brachman 2008); rubber geocomposites (Zanzinger 1999; Tognon et al. 2000); and recycled rubber tire shreds (Reddy and Saichek 1998; Dickinson and Brachman 2008). At present, only thick soil layers have been shown to limit the long-term tensile strain to very small levels $(<2 \%)$ for $50 \mathrm{~mm}$ coarse gravel above a $1.5 \mathrm{~mm}$ thick HDPE geomembrane and at a pressures up to $1000 \mathrm{kPa}$ (Tognon et al. 2000; Gudina and Brachman 2006; Brachman and Gudina 2008a, 2008b; Dickinson and Brachman 2008).

\subsection{Nature of the rupture surface}

A sharp razor blade was used to separate the two sides of the rupture surfaces in-line with but outside the zone where the ruptures occurred in GMB during the GLLS experiments. These surfaces were examined using a stereoscopic microscope and photographed (e.g., Figures 15-17). To aid the discussion of the rupture surfaces, marks were placed on the photographs at locations of surface variations or notable features. The edges of the photographs (beyond the first and the last marks) should be ignored as they are disturbed by the razor blade incision made to expose the rupture surfaces.

Figure 15 shows a $12 \mathrm{~mm}$ long crack located on the side slope of one of the indentations after GLLS experiment at $65^{\circ} \mathrm{C}$. There were locations along the two edges of the crack where the crack did not fully penetrate the full thickness of the GMB as is evident from the intermitted light penetrating the GMB from beneath in Figure 15a. The portion of the crack that was only partially penetrating curved out of the plane of the fully penetrating stress crack (rupture) following the shape of the indentation. The two sides of the crack were separated during the cutting of the GMB to photograph the rupture surface and were on a plane different from the rest of the ruptured surface. The locations (between locations $\mathrm{I}-\mathrm{II}$ and V-VI on Figure $15 \mathrm{~b})$ where the crack was not fully penetrating appear as separated protrusions in the polymer near the bottom surface of the GMB. On the surface of the crack opposite to that shown in Figure $15 \mathrm{~b}$ and corresponding to the separated protrusions shown in Figure 15b there were surface cavities that match these protrusions; they are artifacts of the separation process. Similarly, surface cavities in Figure 15b, between locations IV-V (near the middle of the GMB thickness) had corresponding protrusions on the opposite crack surface (i.e., these are not voids since there was matching material that occupied the cavity in Figure $15 \mathrm{~b}$ on the half not shown.). Similar features are shown in Figure 16c (between locations I-II and $\mathrm{IV}-\mathrm{V}$ ) and Figure 17b (between locations I-II and $\mathrm{V}-\mathrm{VI}$ ) for ruptures at two different indentations in the GMB after the $85^{\circ} \mathrm{C}$ GLLS experiment. In general, the cross-section of the photographed surfaces included different out-of-plane features (protrusions and, on the opposite side, the corresponding cavities) and the photographs shown in Figures 15b, 16c and 17b show their projection on the horizontal plane. Because of their three-dimensionality, these features usually have some shadows from the light source at their boundaries.

A notable out-of-plane feature observed between locations III-IV in Figure 16c is a protrusion of the polymer through its full thickness due to the change of direction of the crack as shown in plan-view in Figure 16b. At this feature the crack (shown by the dark zone in in Figure 16b) diverted from a straight line (in plan-view) between locations III and IV. The vertical shadows appearing in Figure $16 \mathrm{c}$ at the boundaries of the out-of-plane feature between points 1 and 2 and points 3 and 4 are the horizontal projection of the two inclined planes appearing in Figure 16b at these locations when the crack moved toward and away from the camera/light. Similar shadows appear at different out of plane features in the crack between the locations $\mathrm{V}$ and VI and at the boundaries of the crack at locations I and VI. The crack shown in Figure 16 shows that some of the brittle ruptures in the GMB samples had some out-of-plane features.

For the crack shown in Figure 17c, much of the crack surface (i.e., between locations II-IV) completely separated during the GLLS experiment and was a clean rupture surface without the cavities/protrusions seen where material was pulled apart for the photographs between I-II and IV-VI.

For each crack shown in Figures $15-17$, there is a smooth rupture surface at the centre of the crack (between locations II-V in Figure 15b; II-III in Figure 16c and II-IV in Figure 17b). These smooth surfaces (magnified in Figure $15 \mathrm{c}$ for a $65^{\circ} \mathrm{C}$ crack and Figure $17 \mathrm{c}$ for a $85^{\circ} \mathrm{C}$ crack) were very similar for the ruptures at the different temperatures. In each case, the rupture surface was approximately symmetric around the horizontal axis, where top and bottom edges of the GMB are similar in shape and size. The mid-part of the rupture surface has more strained micro-fibrils (evidenced by their white colour). These photos suggest that the cracks at these locations were initiated from both the top and bottom 


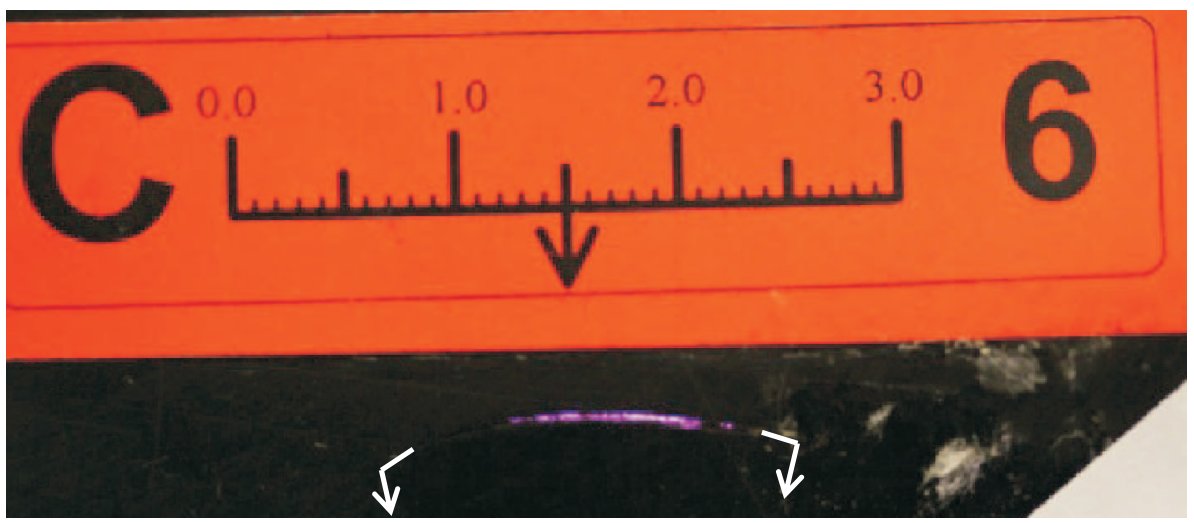

(a)
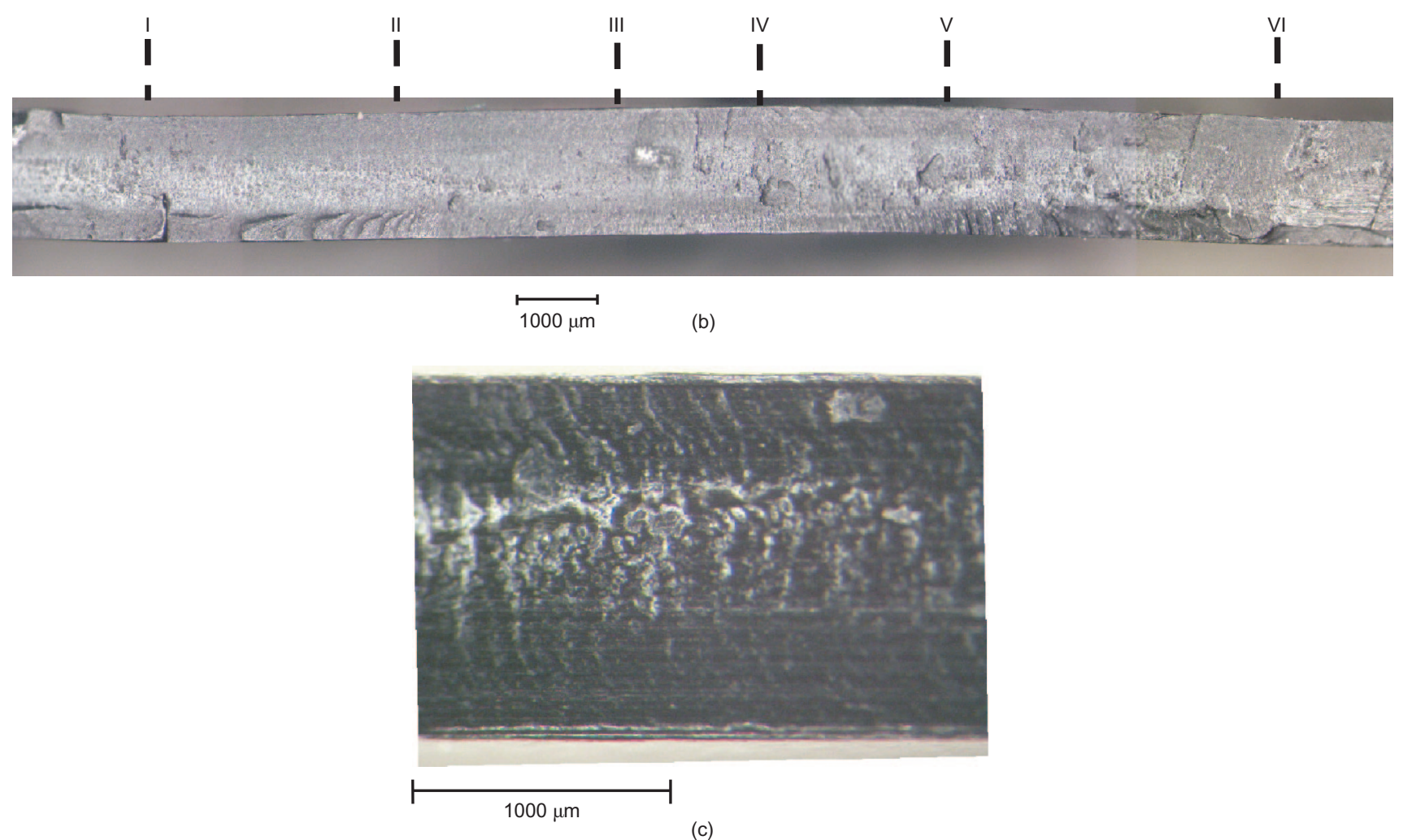

(c)

Figure 15. A $12 \mathrm{~mm}$ rupture after $65^{\circ} \mathrm{C}$ GLLS experiment: (a) plan view with light shining through the rupture in the GMB; (b) cross-section through one face of the rupture shown in Figure15a at $4 \times$ magnification; (c) magnified part of the rupture surface taken between locations II-III at $6.4 \times$ magnification. (Labels I to VI are used to divide the rupture surface at locations of surface variations or notable features)

surfaces of the GMB leaving the middle ligament resisting the full crack propagation until rupture occurred. The formation of the surface cracks would induce higher stresses in the remaining ligament in the mid portion of the GMB, causing more strain in the fibrils prior to failure than was present closer to the GMB surface. To provide support for this inference, a specimen of the same preaged GMB was tested in the SCR test (ASTM D 5397) without a notch at $20 \%$ of its yield strength (to ensure brittle failure). Figure 18 shows the rupture surface where a crack was observed to initiate from both surfaces of the GMB in this SCR test. There is a great deal of similarity between to the failure of the GMB under simulated field conditions (Figures $15 \mathrm{c}$ and $17 \mathrm{c}$ ) and that in this SCR test (Figure 18).

Figure 19 shows a cross-section through several partially penetrating cracks. In Figure 19a there are three small cracks initiating from the top surface of the GMB at a location between two indentations. Figure 19b shows partial propagation of a crack, also located between two indentions, where the initiation is from top surface towards the bottom of the GMB. Figure 19c shows partial propagation of a crack located on the side slope of the indentation with initiation occurring from both the top and bottom surfaces. 


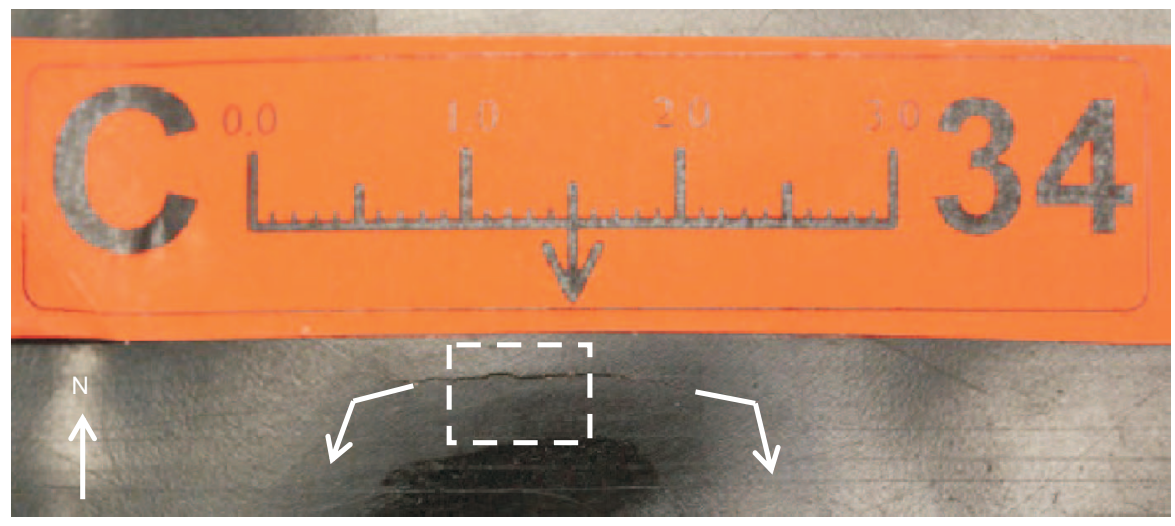

(a)

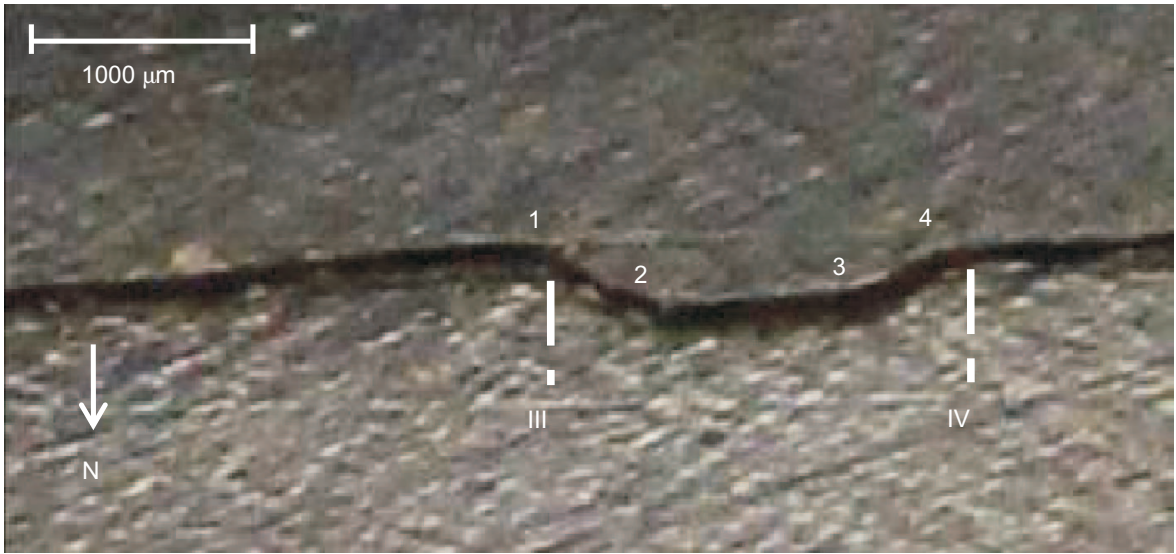

(b)

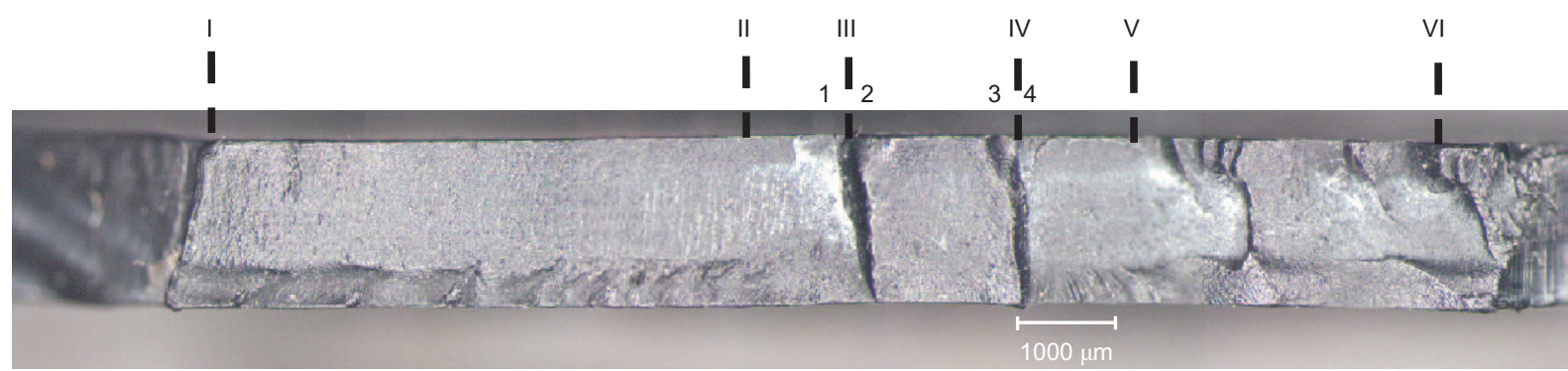

(c)

Figure 16. A $12 \mathrm{~mm}$ crack after $85^{\circ} \mathrm{C}$ GLLS experiment: (a) plan view; (b) enlarged plan view of the section shown in Figure 16a rotated $180^{\circ}$ to match the section shown in Figure 16c; (c) section through the GMB at the location shown in Figure16a at $4 \times$ magnification showing the rupture surface. (Labels I to VI are used to divide the rupture surface at locations of surface variations or notable features)

\section{CONCLUSIONS}

An investigation of the vulnerability of an HDPE geomembrane (GMB) to long-term brittle rupture at local gravel indentations under simulated field condition has been described. GMB samples that had been pre-aged to lower its NCTL-stress crack resistance to $75 \mathrm{~h}$ were tested as part of a composite liner in specially developed geosynthetic liner longevity simulators (GLLSs) at 40, 55, $65,70,75$ and $85^{\circ} \mathrm{C}$. The $1.5 \mathrm{~mm}$ HDPE geomembrane samples were underlain by a hydrated geosynthetic clay liner and overlain by a $560 \mathrm{~g} / \mathrm{m}^{2}$ nonwoven geotextile protection layer and $50 \mathrm{~mm}$ drainage gravel. The experiments were conducted with synthetic leachate circulation in the drainage layer at an applied pressure of $250 \mathrm{kPa}$.
For the specific conditions examined the following conclusions were reached.

1. The GMB experienced stress cracking under simulated field conditions in the GLLS. Three distinct stages were observed in samples after testing in the GLLS: (a) crack initiation, where a small and thin crack was apparent at the GMB surface; (b) partial propagation, where cracks had propagated part way, but not completely, through the GMB; and (c) rupture, where the cracks propagated through the full thickness of the GMB and allowed leakage of leachate through the GMB. 


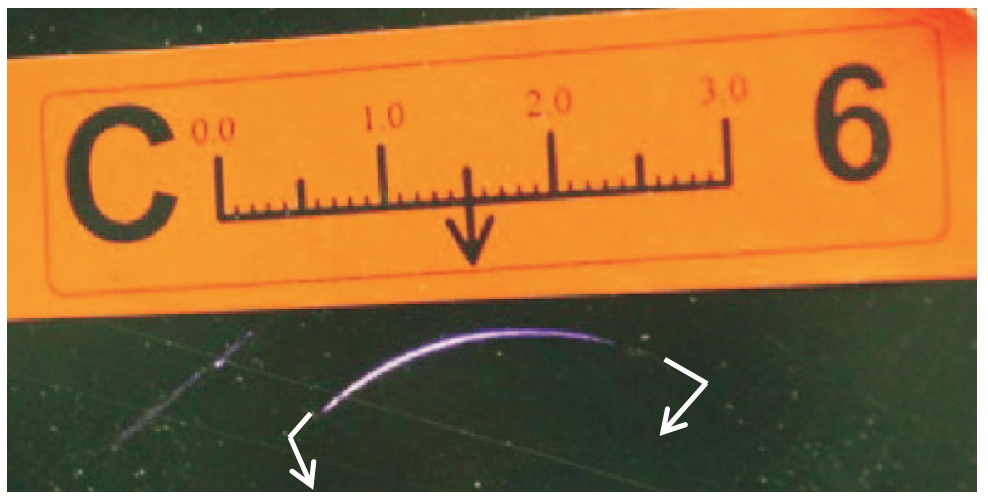

(a)
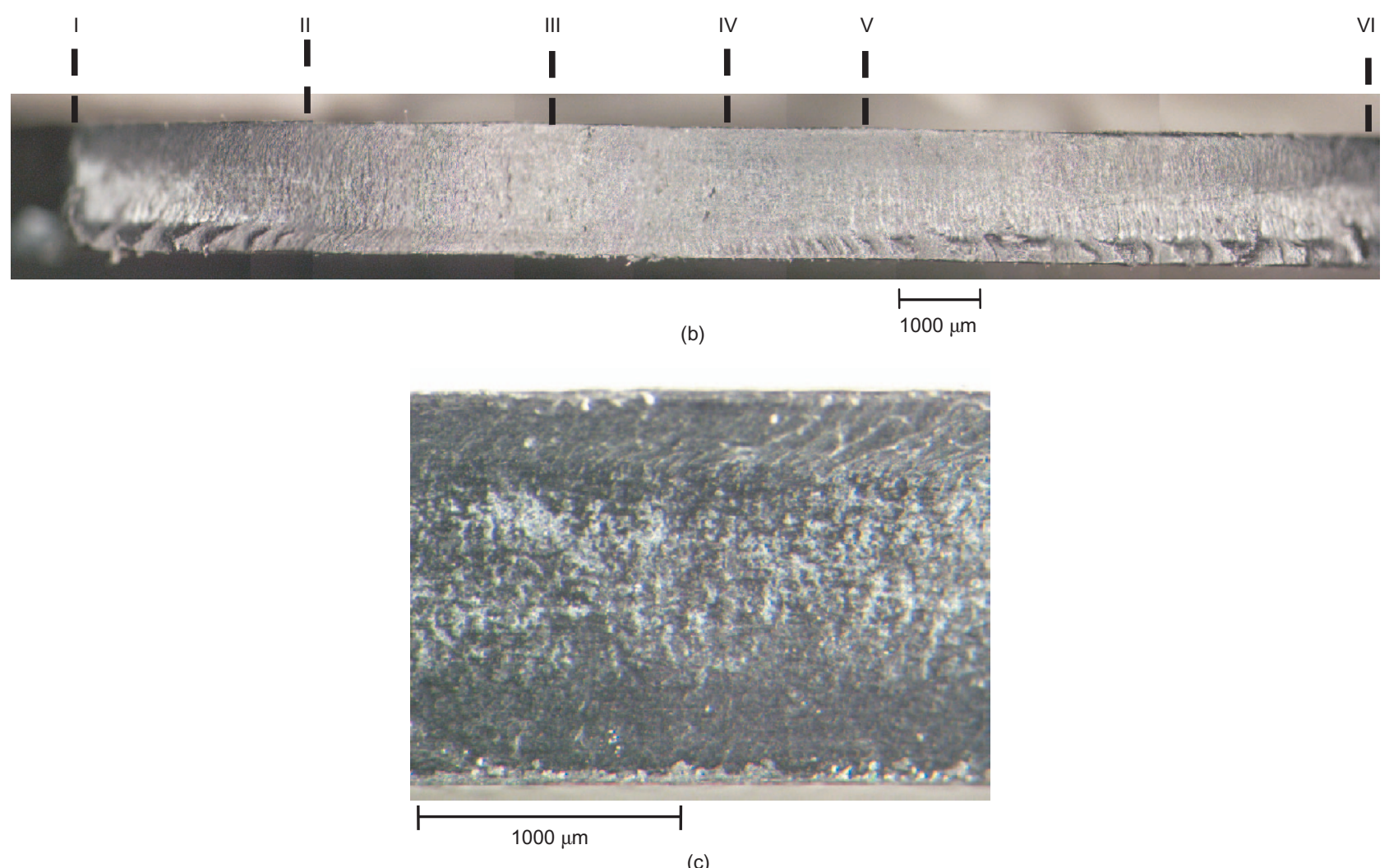

(c)

Figure 17. A $20 \mathrm{~mm}$ crack after $85^{\circ} \mathrm{C}$ GLLS experiment: (a) plan view with light shining through the GMB; (b) section through the GMB at the location shown in Figure 17a at $4 \times$ magnification showing the rupture surface; (c) magnified part of the crack taken between locations III-IV at 6.4 $\times$ magnification. (Labels I to VI are used to divide the rupture surface at locations of surface variations or notable features)

2. The cracks were characteristic of brittle rupture without ductility.

3. The location of cracks was directly related to the presence of gravel particles creating local indentations in the GMB. For these particular tests, all the ruptures were located on the side slope of indentations and initiation took place from the bottom or the top or from both surfaces of the GMB. The majority of cracks were aligned parallel to the machine direction of the GMB, which is the direction with the lowest NCTL-SCR (i.e., tension orientated in the cross-machine direction).

4. There was no correlation between the location of the surface scratches in the GMB prior to the GLLS experiment and the rupture locations (i.e., none of the observed ruptures were initiated from an existing surface scratch) in any of the samples tested. Thus the scratches in the GMBs tested were either not at critical locations (i.e., coincident with local gravel indentations) and/or not deep enough to cause sufficient stress concentration in the GMB to cause a rupture. Thus while scratches are not to be encouraged, and in some cases could contribute to cracking, in these experiments they were not a factor.

5. The higher the GMB temperature, the shorter the time to rupture and the greater the tensile strain at the location of ruptures (other things being equal).

6. Arrhenius modelling was used to provide a time-

Geosynthetics International, 2014, 21, No. 1 


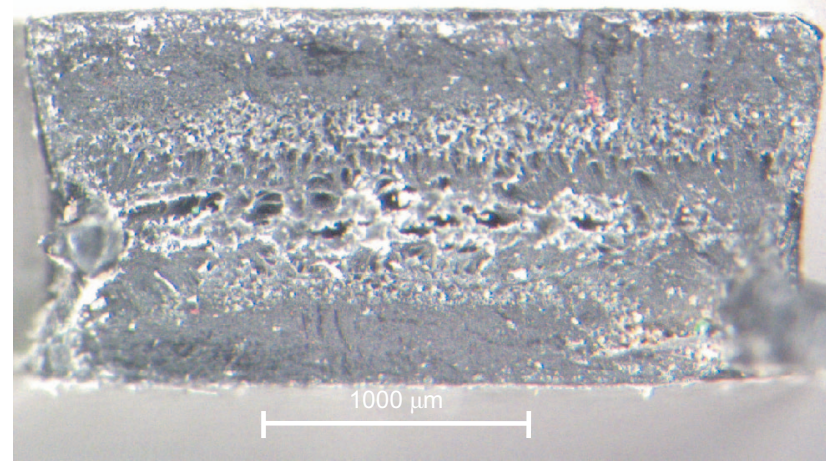

Figure 18. Rupture surface of unnotched constant tensile load specimen tested at $20 \%$ of the yield strength in the cross-machine direction with crack initiation taking place from both surfaces of the GMB at $4 \times$ magnification

temperature shift that would allow the estimation of the time to crack for a GMB at a given SCR and temperature. An activation energy, $E_{\mathrm{a}}=112 \mathrm{~kJ} / \mathrm{mol}$, was calculated for the test temperature range examined $\left(55-85^{\circ} \mathrm{C}\right)$. This value may be revised as more data becomes available at lower temperatures.

7. At the time of writing, the experiment at $40^{\circ} \mathrm{C}$ has been running for 20 months $(>14000 \mathrm{~h}$ ) and failure had not yet been detected. This time exceeds that predicted by Arrhenius modelling based on data at $55-85^{\circ} \mathrm{C}$, suggesting that conditions may change (for the better) below $55^{\circ} \mathrm{C}$ and that the predications based on the temperatures of $55-85^{\circ} \mathrm{C}$ are conservative at $40^{\circ} \mathrm{C}$ and probably lower temperatures.

8. The $560 \mathrm{~g} / \mathrm{m}^{2}$ needle punched nonwoven geotextile used as a protection layer was sufficient to prevent short-term punctures but not the developed indentations which induce tensile strains sufficient to cause stress cracking of the GMB examined. Cracks occurred at calculated strains as low as 6\%, highlighting the need to prevent indentations that cause tensile strains of this magnitude by ensuring an appropriate protection layer between the drainage gravel and GMB. (e.g., a sand protection layer as suggested by Seeger and Müller (1996) and Rowe et al. (2013)).

This study was restricted to examining the performance of a commercially available HDPE GMB aged to $75 \mathrm{~h}$ NCTL SCR. The GMB was part of a composite liner tested under simulated landfill conditions for a single testing configuration. The results have highlighted the need for future studies to investigation of the effects on the time and strain at failure of the: SCR of the GMB, overburden pressure, gravel grain-size, type of protection layer, GMB characteristics (including thickness), and subgrade.

\section{ACKNOWLEDGEMENTS}

Funding for the development of the research infrastructure was provided by the Canada Foundation for Innovation,

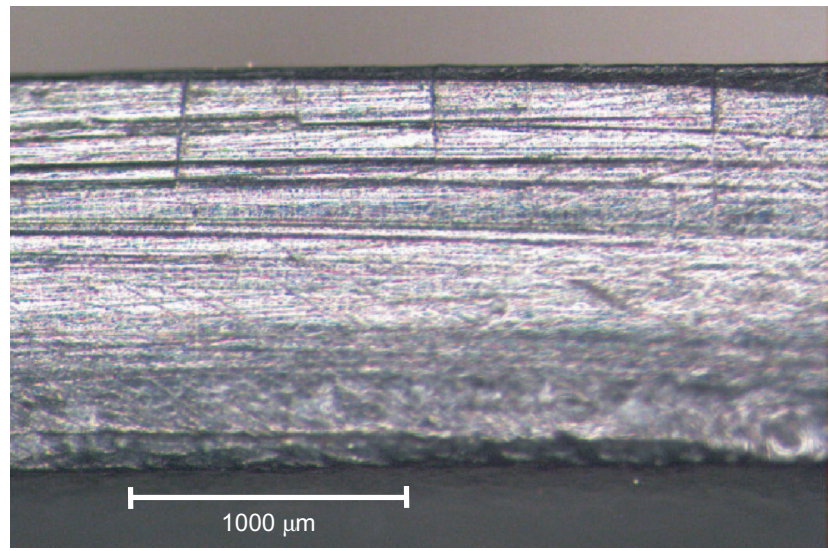

(a)

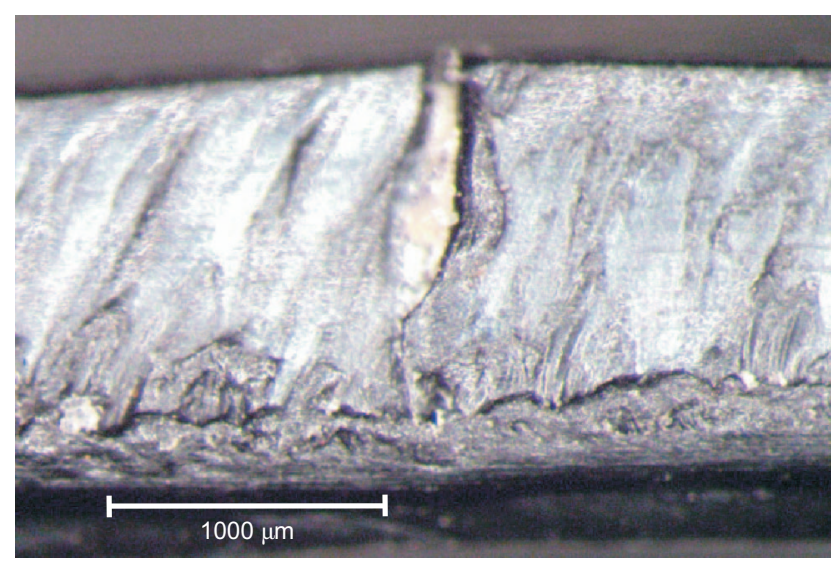

(b)

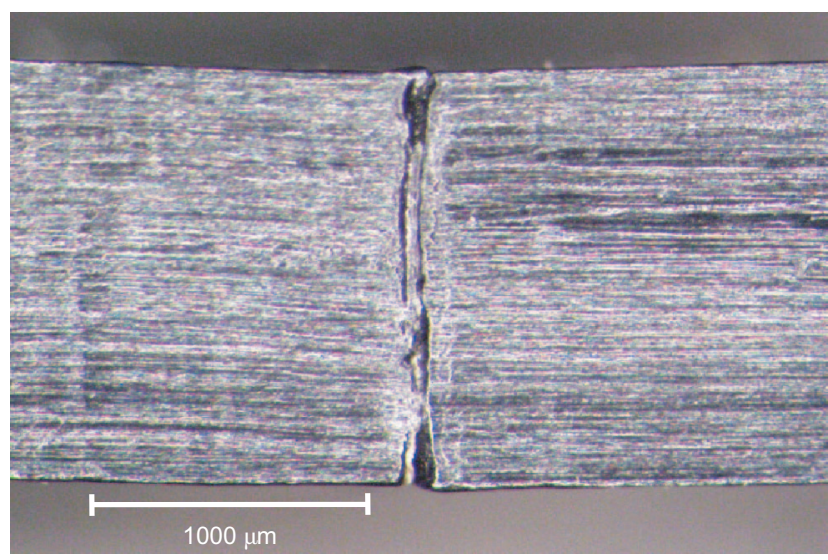

(c)

Figure 19. Cross-section perpendicular to the crack after a GLLS experiment at $85^{\circ} \mathrm{C}$ showing: (a) crack initiation from the top of the GMB between two indentations; (b) partial propagation between indentations where initiation took place from top surface only; (c) partial propagation at the side slope of an indentation where initiation took place from both the top and bottom surfaces. Magnification is $4 \times$

the Ontario Innovation Trust, the Ontario Research Fund Award and Queen's University. The research was being funded by the Natural Sciences and Engineering Research Council of Canada through a Strategic Project Grant and by the Ontario Ministry of the Environment through the Best-In-Science program. The support of the Killam Trust in the form of a Killam Fellowship to R. K. Rowe is gratefully acknowledged. This investigation into the long- 
term performance of geosynthetic liner systems is being done in partnership with the Ontario Ministry of the Environment, Terrafix Geosynthetics Inc., Solmax International Inc., AMEC Earth and Environmental, Gartner Lee, Golder Associates, and CTT Group. The authors highly appreciate the work of M. Z. Islam in incubating and monitoring the geomembrane sheets for the first 20 months of the pre-ageing stage that was presented in the current study. The many valuable contributions by D. N. Arnepalli and E. Safari in the design of the GLLS tests are appreciated. Special thanks also go to B. Muller and C. Mitchell in helping in construction and maintaining the GLLS tests. The authors gratefully acknowledge the value of many discussions with Y. G. Hsuan.

\section{NOTATION}

Basic SI units are given in parentheses.

$A$ empirical constant (per month)

$C_{\mathrm{U}}$ uniformity coefficient (dimensionless)

$D_{85}$ particle diameter at which $85 \%$ of the particles present are finer $(\mathrm{m})$

$D_{50}$ particle diameter at which $50 \%$ of the particles present are finer $(\mathrm{m})$

$D_{10}$ particle diameter at which $10 \%$ of the particles present are finer $(\mathrm{m})$

$E_{\text {a }}$ activation energy $(\mathrm{J} / \mathrm{mol})$

$F_{\mathrm{t}}$ time to failure in GLLS (months)

$R$ universal gas constant $(8.314 \mathrm{~J} / \mathrm{mol}$ per $\mathrm{K})$

$M_{\mathrm{A}}$ mass per unit area $\left(\mathrm{kg} / \mathrm{m}^{2}\right)$

$T$ GLLS test temperature (K)

$w_{\text {opt }}$ standard Proctor optimum water content (dimensionless)

$\rho_{\max }$ maximum dry density $\left(\mathrm{kg} / \mathrm{m}^{3}\right)$

\section{ABBREVIATIONS}

GCL geosynthetic clay liner

GLLS geosynthetic liner longevity simulator

GMB geomembrane

GTX geotextile

HDPE high density polyethylene

HP-OIT high pressure oxidative induction time

MI melt index

MSW municipal solid waste

NCTL-SCR notched constant tensile load test stress crack resistance

Std-OIT standard oxidative induction time

\section{REFERENCES}

Abdelaal, F. B., Rowe, R. K., Smith, M. \& Thiel, R. (2011). OIT depletion in HDPE geomembranes used in contact with solutions having very high and low $\mathrm{pH}$. Proceedings of the 14th PanAmerican Conference on Soil Mechanics and Geotechnical Engineering, Toronto, Canada CD-ROM, 7p.

Abdelaal, F. B., Rowe, R. K., Smith, M., Brachman, R. W. I. \& Thiel, R. (2012). Antioxidant depletion from HDPE and LLDPE geomembranes without HALS in and extremely low $\mathrm{pH}$ solution. The 2nd
Pan American Geosynthetic Conference and Exhibition, GeoAmericas, 2012, Lima, Peru CD-ROM, 9p.

ASTM D 1238 Flow Rates of Thermoplastics by Extrusion Plastometer. ASTM International, West Conshohocken, PA, USA.

ASTM D 1505 Standard Test Method for Density of Plastics by the Density-Gradient Technique. ASTM International, West Conshohocken, PA, USA.

ASTM D 1693 Standard Test Method for Environmental Stress-Cracking of Ethylene Plastics. ASTM International, West Conshohocken, PA, USA.

ASTM D 3895 Standard Test Method for Oxidative-induction Time of Polyolefins by Differential Scanning Calorimetry. ASTM International, West Conshohocken, PA, USA.

ASTM D 4218 Standard Test Method for Determination of Carbon Black Content in Polyethylene Compounds By the Muffle-Furnace Technique. ASTM International, West Conshohocken, PA, USA.

ASTM D 4632 Standard Test Method for Grab Breaking Load and Elongation of Geotextiles. ASTM International, West Conshohocken, PA, USA.

ASTM D 5199 Standard Test Method for Measuring the Nominal Thickness of Geosynthetics. ASTM International, West Conshohocken, PA, USA.

ASTM D 5261 Standard Test Method for Measuring Mass per Unit Area of Geotextiles. ASTM International, West Conshohocken, PA, USA.

ASTM D 5397 Standard Test Method for Evaluation of Stress Crack Resistance of Polyolefin Geomembranes Using Notched Constant Tensile Load Test. ASTM International, West Conshohocken, PA, USA.

ASTM D 5885 Standard Test Method for Oxidative Induction Time of Polyolefin Geosynthetics by High-Pressure Differential Scanning Calorimetry. ASTM International, West Conshohocken, PA, USA.

ASTM D 6693 Standard Test Method for Determining Tensile Properties of Nonreinforced Polyethylene and Nonreinforced Flexible Polypropylene Geomembranes. ASTM International, West Conshohocken, PA, USA.

ASTM D 6747 Standard Guide for Selection of Techniques for Electrical Detection of Potential Leak Paths in Geomembrane. ASTM International, West Conshohocken, PA, USA.

ASTM E 794 Standard Test Method for Melting and Crystallization Temperatures by Thermal Analysis. ASTM International, West Conshohocken, PA, USA.

Borghi, A. D., Binaghi, L., Converti, A. \& Borghi, M. D. (2003). Combined treatment of leachate from sanitary landfill and municipal wastewater by activated sludge. Chemical and Biochemical Engineering Quarterly, 17, No. 4, 277-283.

Brachman, R. W. I. \& Gudina, S. (2002). A new laboratory apparatus for testing geomembranes under large earth pressures. Proceedings of 55th Canadian Geotechnical Conference. CGS, Niagara Falls, ON, Canada, pp. 993-1000.

Brachman, R. W. I. \& Gudina, S. (2008a). Gravel contacts and geomembrane strains for a $\mathrm{GM} / \mathrm{CCL}$ composite liner. Geotextiles and Geomembranes, 26, No. 6, 448-459.

Brachman, R. W. I. \& Gudina, S. (2008b). Geomembrane strains from coarse gravel and wrinkles in a GM/GCL composite liner. Geotextiles and Geomembranes, 26, No. 6, 488-497.

Brachman, R. W. I. \& Sabir, A. (2010). Geomembrane puncture and strains from stones in an underlying clay layer. Geotextiles and Geomembranes, 28, No. 4, 335-343.

Brachman, R. W. I. \& Sabir, A. (2013). Long-term assessment of a layeredgeotextile protection layer for geomembranes. Journal of Geotechnical and Geoenvironmental Engineering, ASCE, 139, No. 5, 752-764.

Brachman, R. W. I., Rowe, R. K., Arnepalli, D. N., Dickinson, S., Islam, M. Z. \& Sabir, A. (2008). Development of an apparatus to simulate the ageing of geomembranes under chemical exposure, elevated temperatures and applied stresses. Proceedings of. GeoAmericas 2008 Conference, Cancun, Mexico 2008, pp. 444-451.

Brachman, R. W. I., Rowe, R. K. \& Irfan, H. (2011). High-pressure puncture testing of HDPE geomembranes. Proceedings of the 14th Pan-American Conference on Soil Mechanics and Geotechnical Engineering, Toronto, October 2011 CD-ROM, 7p.

Brown, N. \& Lu, X. (1995). The fracture mechanics of slow crack growth 
in polyethylene. International Journal of Fracture, 69, No. 4, 371377.

Cooney, J. L. (1964). Effect of morphology on biaxial stress rupture of polyethylene. Journal of Applied Polymer Science, 8, No. 4, 18891901.

Darilek, G. T., Laine, D. \& Parra, J. O. (1989). The electrical leak location method for geomembrane liners. Proceedings of Geosynthetic Conference 1989, IFAI, San Diego, CA, USA, pp. 456-462.

Dickinson, S. \& Brachman, R. W. I. (2008). Assessment of alternative protection layers for a geomembrane/geosynthetic clay liner (GM/ GCL) composite liner. Canadian Geotechnical Journal, 45, No. 11, 1594-1610.

GRI (Geosynthetic Research Institute) (2012). Standard Specification for Test Methods, Test Properties, and Testing Frequency for High Density Polyethylene (HDPE) Smooth and Textured Geomembranes: GRI test method Geomembrane 13. Geosynthetic Research Institute, Folsom, PA, USA.

Gudina, S. K. (2007). Short-term Physical Response of HDPE Geomembrane from Gravel Indentations and Wrinkles. PhD Thesis, Department of Civil Engineering, Queen's University, Kingston, Ontario, Canada.

Gudina, S. \& Brachman, R. W. I. (2006). Physical response of geomembrane wrinkles overlying compacted clay. Journal of Geotechnical and Geoenvironmental Engineering, ASCE, 132, No. 10, 1346-1353.

Gudina, S. \& Brachman, R. W. I. (2011). Geomembrane strains from wrinkle deformations. Geotextiles and Geomembranes, 29, No. 2, $181-189$.

Gulec, S. B., Edil, T. B. \& Benson, C. H. (2004). Effect of acidic mine drainage on the polymer properties of an HDPE geomembrane. Geosynthetics International, 2, No. 11, 60-72.

Hornsey, W. P. \& Wishaw, D. M. (2012). Development of a methodology for the evaluation of geomembrane strain and relative performance of cushion geotextiles. Geotextiles and Geomembranes, 35, 87-99.

Hosney, M. S. \& Rowe, R. K. (2013). Changes in GCL properties after two years in a cover of arsenic-rich tailings. Canadian Geotechnical Journal, 50, No. 3, 326-342.

Hrapovic, L. (2001). Laboratory Study of Intrinsic Degradation of Organic Pollutants in Compacted Clayey Soil. PhD Thesis, University of Western Ontario, London, Ontario, Canada.

Hsuan, Y. G. (2000). Database of field incidents used to establish HDPE geomembrane stress crack resistance specifications.. Geotextiles and Geomembranes, 18, No. 1, 1-22.

Hsuan, Y. G. \& Koerner, R. M. (1998). Antioxidant depletion lifetime in high density polyethylene geomembranes. Journal of Geotechnical and Geoenvironmental Engineering, ASCE, 124, No. 6, 532-541.

Kay, D., Blond, E. \& Mlynarek, J. (2004). Geosynthetic durability: a polymer chemistry issue. CGS. Proceedings of the 57th Canadian Geotechnical Conference, Quebec City, Canada.

Kinloch, A. J. \& Young, R. J. (1983). Fracture Behaviour of Polymers, Applied Science, London, UK.

Kjeldsen, P., Barlaz, M. A., Rooker, A. P., Baun, A., Ledin, A. \& Christensen, T. H. (2002). Present and long-term composition of MSW landfill leachate: a review. Critical Reviews in Environmental Science and Technology, 32, No. 4, 297-336.

Koerner, R. M., Lord, A. E. \& Hsuan, Y. H. (1992). Arrhenius modeling to predict geosynthetic degradation. Geotextiles and Geomembranes, 11, No. 2, 151-183.

Koerner, R. M., Wilson-Fahmy, R. F. \& Narejo, D. (1996). Puncture protection of geomembranes Part III: Examples. Geosynthetics International, 3, No. 5, 655-675.

Koerner, R. M., Hsuan, Y. G., Koerner, G. R. \& Gryger, D. (2010). Ten year creep puncture study of HDPE geomembranes protected by needle-punched nonwoven geotextiles. Geotextiles and Geomembranes, 28, No. 6, 503-513.

Lander, L. L. (1960). Environmental stress rupture of polyethylene. Society of Petroleum Engineers Journal, SPE, 17, 1329-1332.

Lord, A. E., Soong, T. Y. \& Koerner, R. M. (1995). Relaxation behaviour of thermally induced stress in HDPE geomembranes. Geosynthetics International, 2, No. 3, 626-634.

Lu, X. \& Brown, N. (1987). Effect of thermal history on initiation of slow crack growth in linear polyethylene. Polymer, 28, No. 9, 1505-1511.

Lu, X. \& Brown, N. (1990). The transition from ductile to slow crack growth failure in a copolymer of polyethylene. Journal of Material Science, 25, No. 1, 411-416.

Maisonneuve, C., Pierson, P., Duquennoi, C. \& Morin, A. (1997). Accelerated aging tests for geomembranes used in landfills. Proceedings of the 6th International Landfill Symposium, Sardinia '97, Cagliari, Italy, vol. 3, pp. 207-216.

Müller, W. (2007). HDPE Geomembranes in Geotechnics, SpringerVerlag, Berlin, Heidelberg, Germany.

Müller, W. \& Jacob, I. (2003). Oxidative resistance of high density polyethylene geomembranes. Polymer Degradation and Stability, 79, No. 1, 161-172.

Narejo, D., Koerner, R. M. \& Wilson Fahmy, R. F. (1996). Puncture protection of geomembranes. Part II: Experimental. Geosynthetics International, 3, No. 5, 629-653.

MoE (Ontario Ministry of the Environment) (1998). Landfill Standards: A guideline on the regulatory and approval requirements for the new or expanding landfilling sites. Ontario Regulations 232/98, Queen's Printer for Ontario, Toronto, ON, Canada.

Peacock, A. (2000). Handbook of Polyethylene: Structures, Properties and Application, Marcel Dekker, New York, USA.

Peggs, I. D., Schmucker, B. \& Carey, P. (2005). Assessment of maximum allowable strains in polyethylene and polypropylene geomembranes. Geo-Frontiers 2005, American Society of Civil Engineers, Reston, VA, USA.

Reddy, K. R. \& Saichek, R. E. (1998). Performance of protective cover systems for landfill geomembrane liners under long-term MSW loading. Geosynthetics International, 5, No. 3, 287-307.

Rimal, S., Rowe, R. K. \& Hansen, S. (2004). Durability of geomembrane exposed to jet fuel a-1. Proceedings of the 57th Canadian Geotechnical Conference, CGS, Quebec City, pp. 13-19.

Rowe, R. K. (2005). Long-term performance of contaminant barrier systems. 45th Rankine Lecture. Geotechnique, 55, No. 9, 631-678.

Rowe, R. K. (2012). Short and long-term leakage through composite liners. The 7th Arthur Casagrande Lecture. Canadian Geotechnical Journal, 49, No. 2, 141-169.

Rowe, R. K. \& Rimal, S. (2008a). Depletion of antioxidants from an HDPE geomembrane in a composite liner. Journal of Geotechnical and Geoenvironmental Engineering, ASCE, 134, No. 1, 68-78.

Rowe, R. K. \& Rimal, S. (2008b). Ageing of HDPE geomembrane in three composite landfill liner configurations. Journal of Geotechnical and Geoenvironmental Engineering, ASCE, 134, No. 7, 906916.

Rowe, R. K., Islam, M. Z. \& Hsuan, Y. G. (2008). Leachate chemical composition effects on OIT depletion in an HDPE geomembrane. Geosynthetics International, 15, No. 2, 136-151.

Rowe, R. K., Rimal, S. \& Sangam, H. P. (2009). Ageing of HDPE geomembrane exposed to air, water and leachate at different temperatures. Geotextiles and Geomembranes, 27, No. 2, 137-151.

Rowe, R. K., Islam, M. Z. \& Hsuan, Y. G. (2010a). Effect of thickness on the ageing of HDPE geomembranes. Journal of Geotechnical and Geoenvironmental Engineering, ASCE, 136, No. 2, 299-309.

Rowe, R. K., Islam, M. Z., Brachman, R. W. I., Arnepalli, D. N. \& Ewais, A. (2010b). Antioxidant depletion from an HDPE geomembrane under simulated landfill conditions. Journal of Geotechnical and Geoenvironmental Engineering, ASCE, 136, No. 7, 930-939.

Rowe, R. K., Abdelaal, F. B. \& Brachman, R. W. I. (2013). Antioxidant depletion of HDPE geomembrane with sand protection layer. Geosynthetics International, 20, No. 2, 73-89.

Saathoff, F. \& Sehrbrock, U. (1994). Indicators for selection of protection layers for geomembranes. Proceedings of the 5th International Conference on Geotextiles, Geomembranes and Related Products, Singapore, pp. 1019-1022.

Sabir, A. \& Brachman, R. W. I. (2012). Time and temperature effects on geomembrane strain from a gravel particle subject to sustained vertical force. Canadian Geotechnical Journal, 49, No. 3, 249-263.

Sangam, H. P. \& Rowe, R. K. (2002). Effects of exposure conditions on the depletion of antioxidants from high-density polyethylene 
(HDPE) geomembranes. Canadian Geotechnical Journal, 39, No. 6, $1221-1230$.

Scheirs, J. (2000). Compositional and Failure Analysis of Polymers: A Practical Approach, Wiley, Chichester, West Sussex, UK.

Scheirs, J. (2009). A Guide to Polymeric Geomembranes: A Practical Approach, Wiley, Chichester, West Sussex, UK.

Seeger, S. \& Müller, W. (1996). Requirement and testing of protective layer systems for geomembranes. Geotextiles and Geomembranes, 14, No. 7-8, 365-376.

Seeger, S. \& Müller, W. (2003). Theoretical approach to designing protection: selecting a geomembrane strain criterion. Geosynthetics: Protecting the Environment, Dixon, N., Smith, D. M., Greenwood, J. H. \& Jones, D. R. V., Editors, Thomas Telford, London, UK, pp. $137-152$.

Soong, T.-Y. (1995). Effects of four experimental variables on the stress relaxation behavior of HDPE geomembranes. Proceedings of Geosynthetics 1995 Conference, Nashville, TN, IFAI, pp. 1139-1147.

Soong, T.-Y. \& Koerner, R. M. (1999). Behavior of waves in high density polyethylene geomembranes: a laboratory study. Geotextiles and Geomembranes, 17, No. 2, 81-104.

Soong, T.-Y., Lord, A. E. \& Koerner, R. M. (1994). Stress relaxation behavior of HDPE geomembrane. Proceedings of the 5th International Conference on Geotextiles, Geomembranes and
Related Products, Southeast Asia Chapter of the International Geotextile Society, Singapore, pp. 1121-1124.

Tognon, A. R. M., Rowe, R. K. \& Brachman, R. W. I. (1999). Evaluation of sidewall friction for a buried pipe testing facility. Geotextiles and Geomembranes, 17, No. 4, 193-212.

Tognon, A. R., Rowe, R. K. \& Moore, I. D. (2000). Geomembrane strain observed in large scale testing of protection layers. Journal of Geotechnical and Geoenvironmental Engineering, ASCE, 126, No. 12, 1194-1208.

Viebke, J., Elble, E., Ifwarson, M. \& Gedde, U. W. (1994). Degradation of unstabilized medium-density polyethylene pipes in hot-water applications. Polymer Engineering and Science, 34, No. 17, 1354-1361.

Ward, A. L., Lu, X. \& Brown, N. (1990). Accelerated test for evaluating slow crack growth of polyethylene copolymers in Igepal and air. Polymer Engineering and Science, 30, No. 18, 1175-1179.

Witte, R. (1997). Practice-oriented investigations to improve geotextile protective layer systems for geomembranes with regard to their long-term protective efficacy. Advanced landfill liner systems, August, H., Holzlöhner, U. \& Meggyes, T., Editors, Thomas Telford Publishing, London, pp. 270-277.

Zanzinger, H. (1999). Efficiency of geosynthetic protection layers for geomembrane liners: performance in a large-scale model test. Geosynthetics International, 6, No. 4, 303-317.

The Editor welcomes discussion on all papers published in Geosynthetics International. Please email your contribution to discussion@geosynthetics-international.com by 15 August 2014. 